\title{
SELF-ASSEMBLING MACROMOLECULES ON SURFACES
}

\author{
$\mathrm{PhD}$ Thesis
}

Krisztina Nagy

Supervisor: Dr. György Váró

Institute of Biophysics

Biological Research Centre

Hungarian Academy of Sciences

Szeged, Hungary 


\section{Contents}

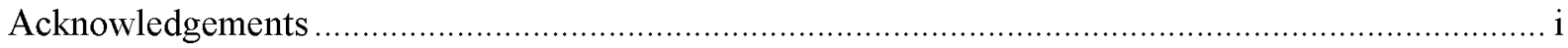

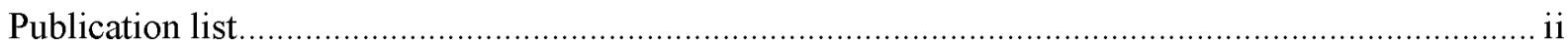

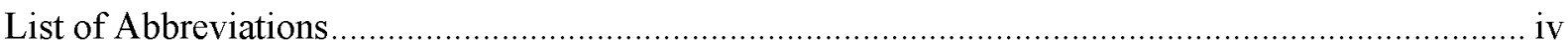

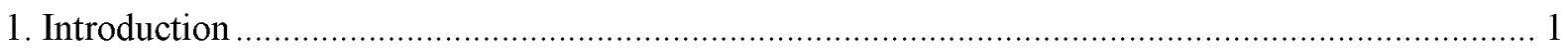

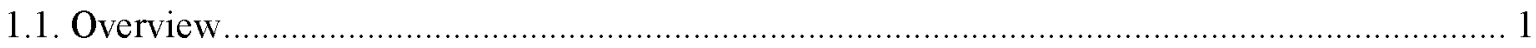

1.2. Studying biological objects at high resolution ................................................................... 2

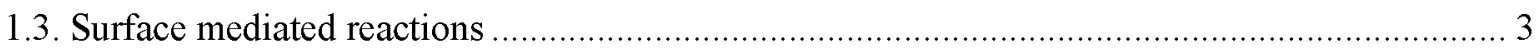

1.4. Surface modification by self-assembling polyelectrolyte films .............................................. 6

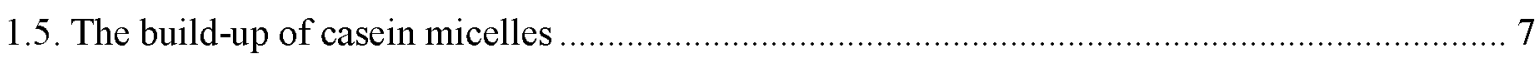

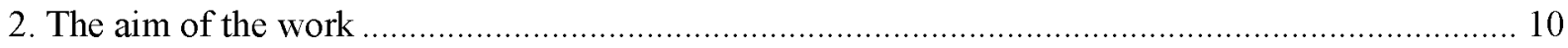

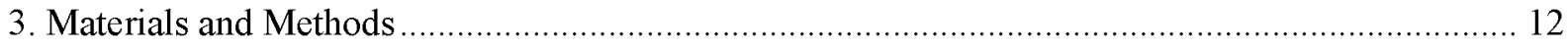

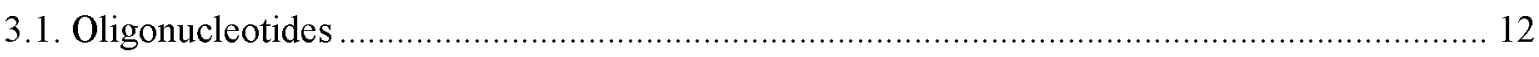

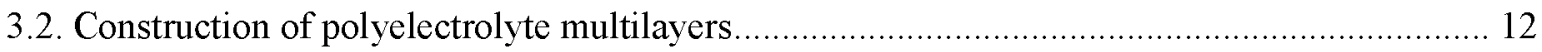

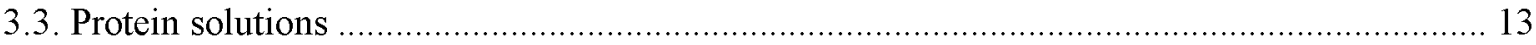

3.4. Basic principles and sample preparation for AFM measurements....................................... 14

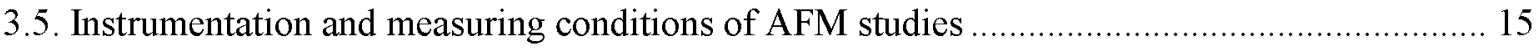

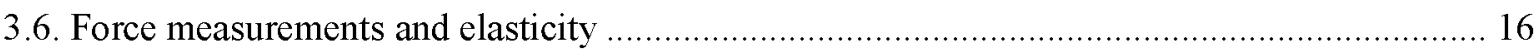

3.7. Attenuated Total Reflection Fourier Transform Infrared (ATR-FTIR) spectroscopy …........... 18

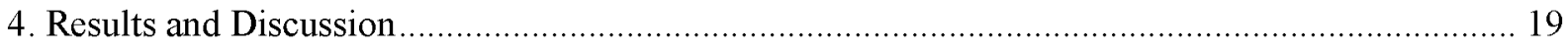

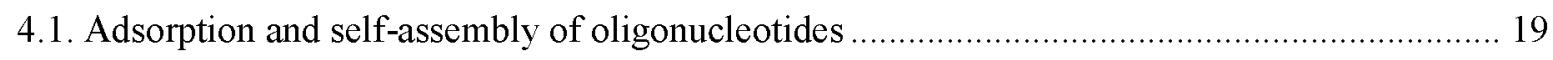

4.1.1. The effect of ODN concentration on the self-assembly …........................................... 20

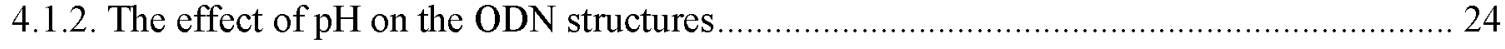

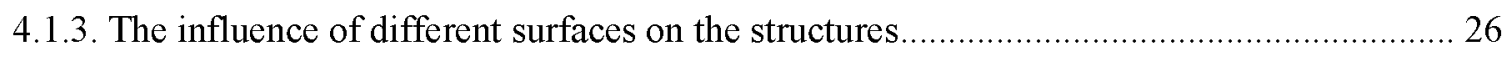

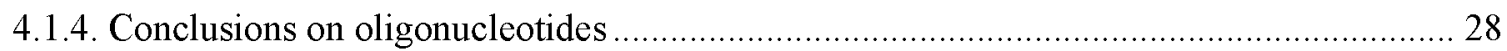

4.2. Step-by-step built of casein aggregates on charged polyelectrolyte film surfaces ................... 29

4.2.1. Casein adsorption onto positively or negatively charged polyelectrolyte surfaces ............ 30 
4.2.2. Aggregation of $\alpha$-casein in the presence of $\mathrm{CaP}$ nanoclusters (PSS-terminated films) ..... 31

4.2.3. Aggregation of $\kappa$-casein in the presence of $\mathrm{CaP}$ nanoclusters (PSS-terminated films) ...... 35

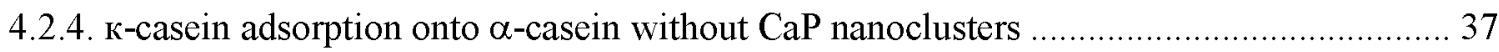

3.2.5. Summing the observations about the casein multilayers .............................................. 41

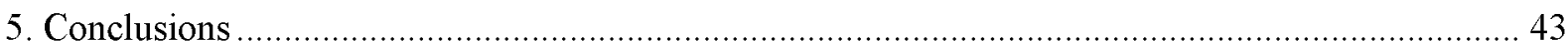

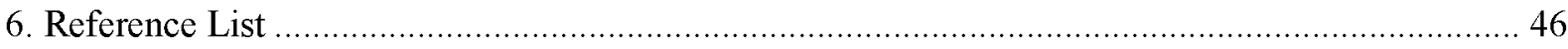

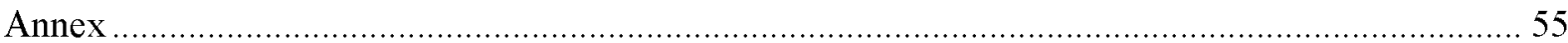




\section{Acknowledgements}

This thesis is the fruit of study and work in the Institute of Biophysics, Biological Research Centre of the Hungarian Academy of Sciences. There are many people who contributed and supported my work.

First and foremost, I would like to express my deepest gratitude to my supervisor, Prof. György Váró. I joined his research group as a $3^{\text {rd }}$ year university student, and from that moment he carefully guided my studies and work. His personality and attitude to science and life impressed me a lot. Our daily discussions about the projects and his advices about the experiments made my work and life easier. I appreciate all his contributions of time, inspiring ideas and funding to make my Ph.D. experience productive and stimulating.

I must express many thanks to Dr. Zoltán Bálint, who introduced me into the world of biophysics and taught me the technique of atomic force microscopy. The technical skills I have learnt from him made it possible for me to implement my thesis.

I gratefully acknowledge the continuous support and the useful advices of my nearest colleagues, Dr. Zsolt Szegletes and Dr. Gergely A. Végh. Their well-intentioned advices often saved me from a lot of difficulties in the lab.

I'm indebted to Prof. Balázs Szalontai for involving me into the studies of polyelectrolytes and caseins. He introduced me the technique of infrared spectroscopy and we often had constructive dialogs about the project.

I would like to thank to Prof. Pál Ormos, the director of Institute of Biophysics and general director of the Biological Research Centre, for providing me the opportunity to work in the Institute. Many thanks to all my colleagues; it was really nice to work in such a creative atmosphere. Thank you for your everyday help and support.

Special thanks go to my family for all their love and encouragement, and to all my friends who were with me during these years. Without them I would have never made it through this process or any of the tough times in my life.

Hungarian Research Foundation (OTKA) grants K-75818 and K-81180 supported this work. 


\section{Publication list}

\section{Papers related to the thesis:}

I. Z. Bálint, K. Nagy, I. Laczkó, S. Bottka, G. A. Végh, Zs. Szegletes, Gy. Váró (2007): Adsorption and Self-Assembly of Oligodeoxynucleotides onto a Mica Surface, Journal of Physical Chemistry C, 111. 17032-17037.

II. K. Nagy, A. Pilbat, G. Groma, B. Szalontai, F.J.G. Cuisinier (2010): Casein Aggregates Built Step-by-Step on Charged Polyelectrolyte Film Surfaces are Calcium Phosphate-cemented, Journal of Biological Chemistry, 285. 38811-38817. IF: 5.329

III. K. Nagy, Gy. Váró, B. Szalontai (2012): K-casein terminates casein micelle build-up by its 'soft' secondary structure, European Biophysics Journal, 41. 959-968. IF: 2.139

\section{Papers not related to this thesis:}

IV. I. Husu, L. Rinyu, K. Nagy, K. Szebenyi, T. Kortvelyesi, M. Giustini, L. Nagy, (2006): Relations between structure and biological affectivity for Q(B) site inhibitors of bacterial photosynthetic reaction centers, Biochimica et Biophysica ActaBioenergetics 275-276 Suppl. S. IF: 4.431

V. L. Nagy, K. Hajdu, B. Fisher, K. Hernádi, K. Nagy, J. Vincze (2010): Photosynthetic Reaction Centres - from Basic Research to Application Possibilities, Notulae Scientia Biologicae 2 (2) 2010, 7-13.

VI. A. G. Végh, Cs. Fazakas, K. Nagy, I. Wilhelm, I.A. Krizbai, P. Nagyőszi, Zs. Szegletes, Gy. Váró (2011): Spatial and Temporal Dependence of the Cerebral Endothelial Cells Elasticity, Journal of Molecular Recognition, 24. 422-428. IF: 3.310

VII. L. Giotta, D. Matrogiacomo, A. Agostiano, F. Italiano,, F., Milano, K. Nagy, M. Trotta, L. Valli (2011): Reversible binding of $\mathrm{Ni}^{2+}$ ions onto bacterial layers revealed by protonation-induced ATR-FTIR difference spectroscopy, Langmuir, 27. 37623773. IF: 4.186 
VIII. K. Hajdu, T. Szabó, M. Magyar, G. Bencsik, Z. Németh, K. Nagy, A. Magrez, L. Forró, Gy. Váró, K. Hernádi, L. Nagy (2011): Photosynthetic reaction center protein in nano structures, Physica Status Solidi B., 248 (11) 2700-2703. IF: 1.316

IX. A. G. Végh, K. Nagy, Z. Bálint, Á. Kerényi, G. Rákhely, Gy.Váró, Zs. Szegletes (2011): Effect of antimicrobial peptide-amide, indolicidin on biological membranes, Journal of Biomedicine and Biotechnology, 2011. 670589. IF: 2.436

X. A. G. Vegh, C. Fazakas, K. Nagy, I. Wilhelm, J. Molnar, I. A. Krizbai, Z. Szegletes, G. Varo (2012): Adhesion and stress relaxation forces between melanoma and cerebral endothelial cells, European Biophysics Journal with Biophysics Letters, 41. 139-145. IF: 2.139

XI. A. Marton, Cs. Vizler, E. Kusz, V. Temesfoi, Zs. Szathmary, K. Nagy, Zs. Szegletes, Gy. Varo, L. Siklos, R. Katona, V. Tubak, O.M. Zack Howard, E. Duda, J. Minarovits, K. Buzas (2012): Melanoma cell-derived exosomes alter macrophage and dendritic cell functions in vitro, Immunology Letters, 148. 34-38. IF: 2.526

XII. T. Szabó, G. Bencsik, M. Magyar, Cs. Visy, Z. Gingl, K. Nagy, Gy. Váró, K. Hajdu, G. Kozák and L. Nagy (2013) Photosynthetic reaction centers/ITO hybrid nanostructure, (2013): Interaction between photosynthetic reaction centers and ITO, Materials Science and Engineering C, 33. 769-773. IF:2.686 


\section{List of Abbreviations}

AC mode alternate contact mode / tapping mode

AFM

atomic force microscopy

ATR-FTIR

attenuated total reflection - Fourier-transform infrared

spectroscopy

CaP calcium-phosphate nanocluster

CM casein micelle

DNA deoxyribonucleic acid

DPPC dipalmitoyl-phosphatidylcholine

HEPES 4-(2-hydroxyethyl)piperazine-1-ethanesulfonic acid

HOPG highly oriented pyrolytic graphite

IDP intrinsically disordered protein

ODN oligodeoxynucleotide

PAH poly(allylamine hydrochloride)

PAA poly(L-aspartic acid)

PEI poly(ethyleneimine)

PGA poly(L-glutamic acid)

PLL poly(L-lysine)

PSS poly(styrene sulfonate)

SPM scanning probe microscopy

STM scanning tunneling microscopy 


\section{Introduction}

\subsection{Overview}

Self-assembling processes are common throughout nature and nanotechnology. There are several reasons for interest in self-assembly, different forms of ordered patterns can be found:

- in living systems,

- in non-living systems, like crystals;

- it gives valuable strategies for synthesis and fabrication, like self-assembled monolayers and lipid bilayers, resulting new properties;

- and it is also a promising area for future applications in robotics, manufacturing, and nanotechnology (Whitesides and Grzybowski, 2002).

Its biological relevance is undeniable. Molecular self-assembly is crucial for living cells. If one would like to understand life, it requires the understanding of self-assembly. The formation of membranes from lipids, the appearance of the double helical deoxyribonucleic acid (DNA) and the assembly of proteins to form their quaternary structures are all important and relevant examples that give reasons why it is a widely studied topic even nowadays.

Beside its biological importance, molecular self-assembly is also an important strategy in nanotechnology, it provides opportunity for making ensembles of nanostructures. The desired structure is programmed into the shape and functional groups of the used molecules. DNA nanotechnology is a hot area in current research, creating complex networks by using the specific molecular recognition properties of nucleic acids, which makes this technique an essential part of nanotechnology. These DNA structures can even be templates for the assembly of other macromolecules like the streptavidin protein (Yan et al., 2003).

Special techniques are needed to study the morphology and structure of macromolecules. Conventional microscopes image by collecting the transmitted or reflected light from the sample. Their resolution is diffraction limited and depends on the wavelength of the radiation used. Higher resolution images can be obtained by using electron microscope, but from biological point of view it has the disadvantage of working in vacuum. The appearance of atomic force microscopy (AFM) helped a lot in the study of biological macromolecules and even living organisms as it works perfectly well in ambient air or in liquid environment. 
I studied the self-assembling properties of oligonucleotides by AFM. These macromolecules consist of 10-20 base pairs, and they are the building blocks of DNA that carries the genetic information. To fulfill their biological function they must have specific self-assembling properties. AFM could provide a direct observation method to study the appearing structures under different conditions. The sub-nanometer resolution of this technology is ideal for mapping the macromolecules.

I also studied the aggregation properties of caseins. These proteins tend to aggregate and usually form micelles in vivo. Casein micelles have a crucial role in calcium and phosphate transport of mammals (Farrel et al., 2006). The proper mechanism of micelle-formation is still unknown. In order to understand the self-association of these proteins better, I created casein layers fixed on charged surfaces and followed their step-by-step aggregation.

\subsection{Studying biological objects at high resolution}

In the early 1980s a new family of microscopes, the scanning probe microscopy (SPM) appeared, its principle was totally different from that of light or electron microscopy. The first member of this family, the scanning tunneling microscope (STM) was invented by Gerd Binnig and Heinrich Rhorer (Binnig and Rhorer, 1984). This development earned them the Nobel Prize for Physics in 1986.

The second member of the SPM family was the atomic force microscope. It was presented by Binnig and his colleagues in 1986 (Binnig, et al., 1986). These instruments are able to record surface topography with atomic resolution (tenth of a nanometer), based on monitoring of the cantilever deflection caused by the surface roughness dominated by van der Waals interactions. Because of its versatility, AFM has been applied to many field of biology. Its main advantages are:

- atomic resolution,

- possibility of in situ imaging,

- and measuring either in air or in liquid.

Since DNA could be readily bound to surfaces and because of its biological relevance, DNA was one of the first biological materials being investigated by AFM (Hansma et al., 1996), and it is even now intensively studied. Its shape and size also makes it suitable for AFM imaging. Single-, double- and triple-stranded DNA molecules deposited on mica and 
silicon surfaces had been observed by Hansma and co-workers. They showed that the structure of the DNA molecules depends on the length and number of the strands (Hansma et al., 1996). AFM is also an important tool in the study of the tertiary conformation of DNA in different environments relevant to biological experiments and biotechnical applications (Hansma et al., 1997; Costa et al., 2004). Different forms and types of DNA have been observed, and also DNA-protein interactions were extensively studied (Anselmetti et al., 2000; Bennink et al., 2003).

Fragments of DNA, the oligonucleotides (ODN) are also intensively studied. Several studies are dealing with the aggregation and self-assembly properties of the ODNs on different surfaces, such as silanized mica (Cheung et al., 2003), polystyrene thin films (Munos-Serrano et al., 2005) and highly oriented pyrolytic graphite (HOPG) (Paquim et al, 2006). Laczkó and co-workers studied ODN-protein interactions using the same type of 18mer ODNs as we used in our experiments (Laczkó et al., 2006; Bálint et al., 2007).

Besides DNA, other macromolecules like membrane proteins (Muller et al., 1995; Muller et al, 1997) and titin molecules were also investigated by AFM (Kellermayer et al, 2003). Even living cell studies were carried out. One of the most intensively studied cell type by AFM is the endothelial cell (Braet et al., 1997; Bálint et al., 2007). Its mechanical characteristics (Mathur et al., 2001; Vegh et al., 2011), cell-cell interactions (Vegh et al., 2011) and the effect of drugs (Oberleithner et al., 2003) have been investigated.

\subsection{Surface mediated reactions}

In order to study macromolecules by AFM the sample should be mounted on a hard surface. From practical point of view this surface should be smooth and clean enough to be able to observe molecules like DNA, oligonucleotides or small proteins on it. One of the most popular mineral that is used for AFM experiments is the muscovite mica. The muscovite mica $\left(\mathrm{K}_{2} \mathrm{Al}_{4} \mathrm{Si}_{6} \mathrm{AL}_{2} \mathrm{O}_{20}(\mathrm{~F}, \mathrm{OH})_{4}\right)$ is a light-colored, non-conductive, hard mineral. Its layered structure consists of aluminum silicate sheets and potassiumions held together by weak interactions. The lattice structure of this mineral is shown on Figure 1. The potassiumions are wedged in a hole between 12 oxygen atoms, 6 from the upper and 6 from the lower layer (Figure 1). These potassium-oxygen bonds are weak and can be easily broken. The cleavage 
surface is characterized by partially delocalized negative charges in combination of weakly bound, localized positive charges of $\mathrm{K}^{+}$-ions (Berry et al., 1983).

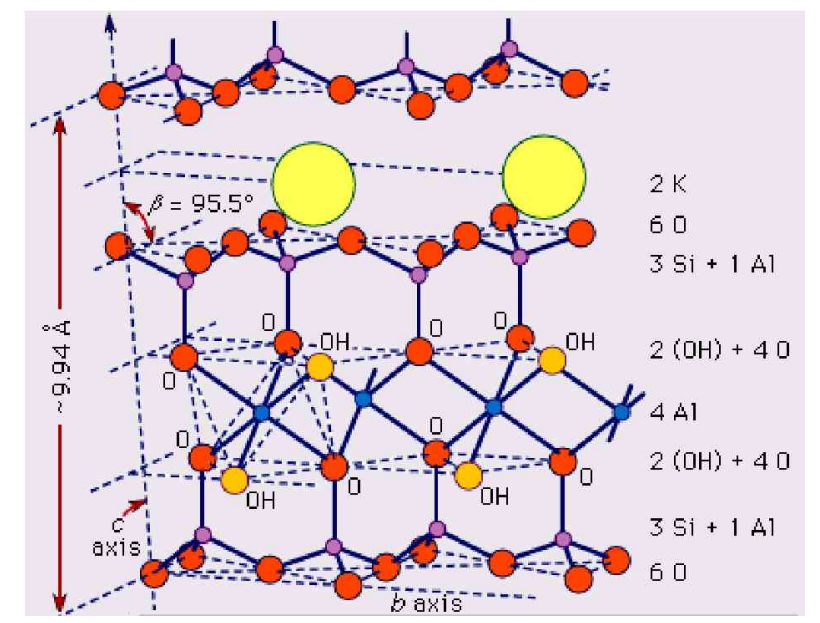

Figure 1. The lattice structure of muscovite mica

The negatively charged surface of the cleaved mica gives opportunity for several surface modifications that can support the immobilization of different macromolecules. It can be even covered by polyelectrolytes, which are able to alter the net charge of the surface. Its atomically flat surface provides a convenient platform for the investigation of few-nanometer sized molecules.

Reactions taking place on different surfaces are well known for a long time, and they are being applied for several tasks, such as fabrication processes and biotechnological purposes (enzyme catalysis). The role of minerals in catalytic, stereospecific polymerization of biologically important macromolecules had been discovered long ago (Bernal, 1951). Several studies confirmed that surfaces have important functions (Pontes-Buarque et al., 2000), such as:

- reactants can accumulate on mineral surfaces;

- temporary complex-formation can take place, decreasing the activation energy;

- condensation reactions of biological precursor molecules can be catalyzed;

- they can serve as templates for nucleotide polymerization;

- they can also support stereoselective effects.

In the recent years numerous observations have reinforced the hypothesis of surfacemediated origin of life (Sowerby et al., 2001; Franchi et al., 2003; Ferris, 2005). The high 
affinity of DNA for mineral surfaces, such as montmorillonite clay or mica makes this hypothesis very plausible.

Allemand and co-workers showed that specific binding of DNA can be achieved on a great variety of surfaces (such as polystryrene, clean glass, polylysine, polyhystidine or amino-silane coated surfaces) by judicious choice of $\mathrm{pH}$. On all of the surfaces the same behavior was observed: at low $\mathrm{pH}$ DNA adsorbs strongly, whereas at high $\mathrm{pH}$ it adsorbs very weakly to the surface. At $\mathrm{pH}$ around 5.5 they found a very specific and strong interaction: at this $\mathrm{pH}$ the DNA is more likely to bind onto hydrophobic surfaces by an extremity rather than by a midsegment (Allemand et al., 1997).

Self-assembly is also recognized as a very efficient method in nanotechnology (Winfree et al., 1998). Controlled assembly of DNA molecules into highly oriented interlaced patterns could provide future application as molecular building blocks of nanotechnology. Selfassembling of the $\lambda$-DNA was observed on a silanized mica surface (Xiao et al., 2003). By using polymer-functionalized DNA deposited and dried onto a polycarbonate-coated glass substrate and using a special technique, formation of nanowires was also observed with AFM (Nakao et al., 2005). This was an important step toward the construction of functional nanodevices using DNA and other biomolecules.

A simple method was established to assemble an ODN monolayer onto unoxidized crystalline silicon (Cattaruzza et al., 2006). By studying the adsorption of ODN to HOPG, different adsorption patterns were observed, depending on the molecular mass or the hydrophobic character of the individual bases, on the secondary structure and also on the $\mathrm{pH}$ (Paquim et al., 2006). Adsorption to gold surfaces was also investigated. ODNs thiolated at the 5' end bind specifically via gold-sulfur linkage and the binding kinetics shows a two-step mechanism (Mourougou-Candoni et al., 2003).

Self-aggregation of ODN or DNA onto mica surface in the presence of different cations (such as $\mathrm{K}^{+}, \mathrm{Mg}^{2+}, \mathrm{Ni}^{2+}$ ) was intensively studied (Sha et al., 1999; Sitko et al, 2003). Sha and co-workers observed that certain ions $\left(\mathrm{Mg}^{2+}\right)$ help, while others $\left(\mathrm{K}^{+}\right)$block the self-assembly of trinucleotides: depending on which ions they used, different structures appeared on the surface. ODNs with different sequences and chain-lengths showed diversity in the structure of the aggregates (Sha et al., 1999). It has been also shown that the charged surface of mica interacts with other macromolecules, like amyloid fibrils. Karsai and co-workers investigated the orientation of amyloid fibrils on freshly cleaved mica surface, and they found a strong $\mathrm{K}^{+}$ 
-sensitivity and specificity of the protein binding (Karsai et al., 2007). They also suggest the application of these oriented networks of amyloid fibrils in nanotechnology (Karsai et al., 2008).

A part of this work was to investigate the conditions for self-assembly of ODNs onto mica surfaces. The observation that the nucleic acid bases and ODN adsorb onto muscovite surfaces, which are similar composition to the montmorillonite clay, may contribute to the understanding of the origin of life (Sowerby et al., 2001; Franchi et al., 2003.).

\subsection{Surface modification by self-assembling polyelectrolyte films}

Self-assembling polyelectrolyte films formed by alternating adsorption of oppositely charged polyions at solid/liquid interface have been introduced by Decher, as a new method to modify surfaces in a controlled way (Decher, 1997). By deposition of a polycation and a polyanion layer-by-layer on a charged surface, polyelectrolyte films called polyelectrolyte multilayers can be constructed. By varying the electrolytes and/or the build-up conditions, the properties of the films such as thickness (Shiratori and Rubner, 2000), cell adhesion (Richert et al., 2002; Picart, 2008), or protein adsorption capacity can be altered at will (Gergely et al., 2004). The surface properties can be modified for several practical applications like biomedical functionalities (Etienne et al., 2005; Benkirane-Jessel et al., 2004; Boudou et al., 2009) and electrooptical devices (Eckle and Decher, 2001). For the accurate control of the incorporation of biological compounds into these films, the structural properties and the adhesive behavior of the electrolytes should be well-known. Therefore structural and mechanical properties of polyelectrolyte multilayer films have been intensively studied by AFM and also by spectroscopic methods, such as FTIR spectroscopy (Mermut et al., 2003; Gong et al., 2005; Menchaca et al., 2003; Pilbat et al., 2006). The most commonly used polycations are: poly(ethyleneimine) (PEI), poly(allylamine hydrochloride) (PAH) and poly(L-lysine) (PLL); and polyanions are: poly(styrene sulfonate) (PSS), poly(L-aspartic acid) (PAA) and poly(L-glutamic acid) (PGA).

Proteins may adsorb either to positively or negatively charged polyelectrolyte films. It has been shown that the charge of the last layer determines mostly the adsorption of a protein (Ladam et al., 2002). An important question is whether the proteins embedded in polyelectrolyte films still keep their original structure and function. Using attenuated total 
reflection Fourier transform infrared spectroscopy (ATR-FTIR), it has been shown that proteins can adsorb onto polyelectrolyte films, and their native secondary structure is little affected (Scwinté et al., 2002). In addition, once a protein had been adsorbed, its secondary structure stabilized by the interaction with the polyelectrolyte film (Shwinté et al., 2001). Szyk-Warszynka and co-workers used $\alpha$ - and $\beta$-casein as polyanionic layers for film build-up. They showed that casein embedded in PLL electrolyte preserves its ability to bind calcium ions (Szyk-Warszynka et al., 2009). Even dynamical behavior studies could be carried out, the lateral diffusion of human serum albumin was investigated in PAH/PSS multilayers (Szyk et al., 2002).

Besides incorporating proteins into the polyelectrolyte multilayers, there is also a possibility to create biomembrane-like barriers using phospholipid bilayers by a layer-bylayer method (Pilbat et al., 2007). There are also studies for creating biodegradable nanoparticles for drug delivery applications. Pan and co-workers used lysozyme and $\beta$-casein to fabricate polyelectrolyte complex micelles and studied the self-assembly of these proteins under different experimental conditions (Pan et al., 2007).

Supported phospholipid membranes have been used as biomimetic model systems to study the biophysical and biochemical properties of biological membranes. These lipid bilayers and monolayers were readily adopted for high resolution AFM imaging (Goksu et al., 2009; Kirat et al., 2010; Woodward and Meuse, 2009). Muscovite mica can provide a surface for creating lipid bilayers from dipalmitoyl-phosphatidylcholine (DPPC). Morandat and Kirat have studied the interaction of cytochrome $c$ protein with this type of model system (Morandat and Kirat, 2011) using AFM. Using polyelectrolyte films as supporting surface for the lipid bilayer can even give a better mimetic system of biological membranes. The effect of an antimicrobial peptide amide, indilicidine has been tested on such system (Végh et al, 2011).

\subsection{The build-up of casein micelles}

Caseins are part of the milk transport system. They are a family of phosphorylated proteins $\left(\alpha_{\mathrm{s} 1}, \alpha_{\mathrm{s} 2}, \beta\right.$ and $\kappa$ caseins), which form a complex with calcium and phosphate ions, and thus make calcium and phosphate available for biological processes. For fulfilling their biological function, caseins are organized into micelles. They have the tendency to self-associate or 
interact with one another, in a process that is driven by hydrophobic interactions. However, the details of their build-up and structure are still unknown. These casein micelles can transport calcium and phosphate at concentrations well beyond the levels that would precipitate in the absence of these proteins (Swaisgood, 1992).

The details of proper mechanism of the self-assembly and structure of casein micelles in solution is an intensively studied area for many years. Different techniques have been used for studying the structure and the stability of the aggregated caseins. Morphological and elasticity studies on the hierarchical networks of casein proteins have been carried out by AFM (Uricanu et al., 2004). Martin and his coworkers probed the interactions of casein micelles with polysaccharides using scanning electron microscopy on gold-coated surfaces (Martin et al., 2006). FTIR and light scattering experiments are also popular for studying the structure and stabilizing interactions of the micelles (Gebhardt et al., 2006.). Regarding its biological function, several studies are dealing with the interaction of calcium ions and casein proteins (Vessely et al., 2005; Müller-Buschbaum et al., 2007; Szyk-Warszynska et al., 2009). The effect of calcium concentration on spin-coated casein films have been studied by AFM. It has been shown that the increasing concentration of $\mathrm{Ca}^{2+}$-ions causes the appearance of large aggregates. Two different types of micelles were identified according to their sizes. They showed the coexistence of $\sim 20 \mathrm{~nm}$ sized sphere like structures, so called mini-micelles, and casein micelles. Addition of $\mathrm{Ca}^{2+}$-ions alters the interactions between the micelles: With the increasing amount of calcium added, the casein micelle size and distances between neighbored micelles decreased (Müller-Buschbaum et al., 2007).

Regarding the micelle structure, several models have been proposed over the years (Horne, 2002; Farrell et al., 2006; Qi, 2007). As principle of casein micelles (CM) organization, two alternative models emerged. According to the submicelle model, via hydrophobic interactions, caseins first form small subunits - submicelles $(\sim 15-20 \mathrm{~nm})$, these units are then connected with each other by calcium-phosphate nanoclusters $(\mathrm{CaP})$ (Walstra, 1999). Recently, the coexistence of submicelles with CM in thin, spin-coated films has been shown (Müller-Buschbaum et al., 2007). The other - copolymer - model does not assume submicelles, it considers the $\mathrm{CaP}$ nanoclusters as nuclei for micelle growth by making contact with the phosphoseryl residues of several casein molecules (Holt et al., 2003). According to the models all casein micelles have the Ca-sensitive $\alpha$ - and $\beta$-caseins in their interiors, while 
the Ca-insensitive $\kappa$-caseins are at the surfaces of the micelles, which is very important from the stability point of view.

From the micelle formation point of view, it is important to know that caseins belong to the family of intrinsically disordered proteins (IDPs). IDPs do not have classical secondary structures, which could be described by characteristic proportion of $\alpha$-helices, $\beta$-sheets, turns, and certain unordered segments. IDPs can adopt several different structures even among similar conditions. The differences between these conformers do not affect the protein's ability to perform its biological function (Tompa, 2005).

Since the tendency of forming aggregates in the presence of $\mathrm{Ca}$ is an inherent property of caseins, it is difficult to study the nature of the interactions, which lead to the formation of the micelles; only the result can be seen. To overcome this problem, we applied a 'nanotechnological' approach; by fixing casein monolayers on charged surfaces. Thus, we could construct 'step-by-step' aggregated casein architectures, and study the effect of the presence of calcium-phosphate nanoclusters on the aggregation. 


\section{The aim of the work}

The objective of this work is to study self-assembling macromolecules on certain surfaces: (i) characterizing the self-assembling properties of the building blocks of DNA on muscovite mica surface, and (ii) investigating the build-up of casein complexes on polyelectrolite surfaces.

i. The conditions for self-assembly of ODNs were studied on mica surface. Our aim was to determine how different physical-chemical parameters affect the evolving structures.

- We assumed that the specific assembling pattern is concentration-dependent. Therefore the appearance of different structures was aimed to show in the function of ODN concentration.

- The $\mathrm{pH}$ of the used media is another important parameter to control. It can influence the distribution of the charges on the surface, and the protonation of the acidic/basic groups of the ODNs. Our aim was to define the conditions that are most specific for the assembling properties.

- After getting an insight into the optimal conditions for the self-assembly on the surface of muscovite mica, we test other surfaces as well, such as HOPG, ntype silicon and glass.

The information gathered from these studies can lead us to some general conclusions about the role and importance of different surfaces in the catalytic, stereospecific reactions of biologically important macromolecules, such as oligonucleotides.

ii. To understand the Ca-phosphate carrying capacity of the casein micelles, the structure and the construction principle of these micelles have to be understood.

- We use casein monolayers fixed on a charged surface for studying individual steps of casein aggregation. The structural properties of the polyelectrolyte film and the planar protein layer were studied by AFM and FTIR spectroscopy.

- Our aim was to study in which conditions calcium- and phosphateions can be incorporated, and further casein layers added. Toward this end, an $\alpha$-casein 
monolayer was formed and studied. The effect of the net charge of polyelectrolyte surface on the aggregation was also tested.

- Former studies and models suggest that $\kappa$-casein terminates the micelle build up, however no direct experimental evidence existed in the literature supporting this assumption. To test this hypothesis we build multilayers from $\alpha$ - and $\kappa$-caseins in the presence/absence of calcium-phosphate nanoclusters between the adsorption steps.

Our experiments can deepen our knowledge of the micelle build-up and thus contribute to the better understanding of the mechanism of calcium-phosphate transport in mammalians 


\section{Materials and Methods}

\subsection{Oligonucleotides}

The 18mer ODN with the sequence 5' GAGCTGCACGCTGCCGTC 3' was synthesized with an Expedite 8909 synthesizer (Applied Biosystems, USA). Double HPLC purification was performed on Kromasil 100-C18 250 x $10 \mathrm{~mm}$ ID column, using $0.1 \mathrm{M}$ acetonitriletriethylammonium acetate mixtures at $\mathrm{pH} 7$ as eluent, resulting in the triethylammonium salt of ODN.

The ODN samples were synthesized and provided by our coworkers: Dr. Sándor Bottka and Prof. Ilona Hollósiné Laczkó.

Fifty microlitres of a 5 to $500 \mathrm{nM}$ aqueous solution of ODN were dropped onto a freshly cleaved muscovite mica surface, and dried for $1 \mathrm{~h}$ under a continuous flow of highly purified air.

\subsection{Construction of polyelectrolyte multilayers}

The charged surface, governing the adsorption of casein onto the surface, was a "layer-bylayer" polyelectrolyte film built according to the method of Decher (Decher, 1997) from $1 \mathrm{mg} / \mathrm{ml}$ solutions of poly(styrene sulfonate) (PSS; MW $=70,000 \mathrm{~g} / \mathrm{mol}$ ) and poly(allylamine hydrochloride) (PAH; $\mathrm{MW}=60,000 \mathrm{~g} / \mathrm{mol}$ ), having a negative or positive charge respectively.

For the AFM experiments, freshly cleaved $1 \times 1 \mathrm{~cm}^{2}$ mica surfaces were used as support for the polyelectrolyte films. The building of the film was started with PAH adsorbed to the mica from $400 \mu \mathrm{l}$ volume, and then the surface was washed two times with buffer (HEPES, $10 \mathrm{mM}, \mathrm{pH}$ 7). After washing, PSS, also from the same volume, was adsorbed onto the PAH layer, and washed again. These steps were repeated until the (PAH/PSS) 6 architecture was achieved. This architecture was aimed, because according to earlier experience, this is the minimum one, which covers more or less totally the surface of a support (Lavalle et al., 2002). Finally, casein was adsorbed from $400 \mu \mathrm{l}$ solution of $0.1 \mathrm{mg} / \mathrm{ml}$ concentration (Figure 2A). 
For the ATR-FTIR measurements polyelectrolytes were let to adsorb onto the surface of the ATR crystal from solutions circulated by a peristaltic pump (Schwinté et al., 2001). Extensive washing periods separated the administrations of the alternating positively or negatively charged polyelectrolytes. To cover the ATR crystal an initial layer of poly(ethyleneimine) (PEI; MW=750,000 g/mol) was used. After the deposition of each layer, a single beam infrared spectrum was recorded to monitor the build-up of the film. Finally, $\alpha$ casein $(0.1 \mathrm{mg} / \mathrm{ml})$ was circulated above the completed film, and after the saturation of the adsorption, there was a washing with HEPES buffer (10 mM, pH 7) (Figure 2B). Calciumphosphate nanoclusters $(\mathrm{CaP})$ were formed on protein surfaces by circulating high concentration of $\mathrm{Ca}^{2+}$-ions in the form of $1 \mathrm{M} \mathrm{CaCl}_{2}$. Then, without washing away the Casolution, a solution of $50 \mathrm{mM} \mathrm{Na} \mathrm{HPO}_{4}$ was introduced into the sample holder by a peristaltic pump. All white precipitate (i.e. the excess insoluble fraction of the formed $\mathrm{CaP}$ ) was removed by washing the film thoroughly with HEPES buffer. The characteristic phosphate vibrational bands in the $1200-1000 \mathrm{~cm}^{-1}$ region of the infrared spectrum recorded after the washing, evidenced the presence of $\mathrm{CaP}$ on the protein surface.

A

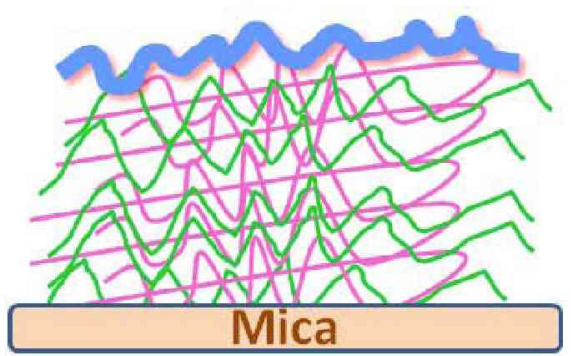

B

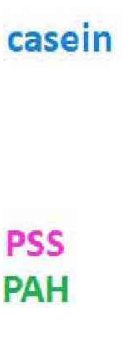

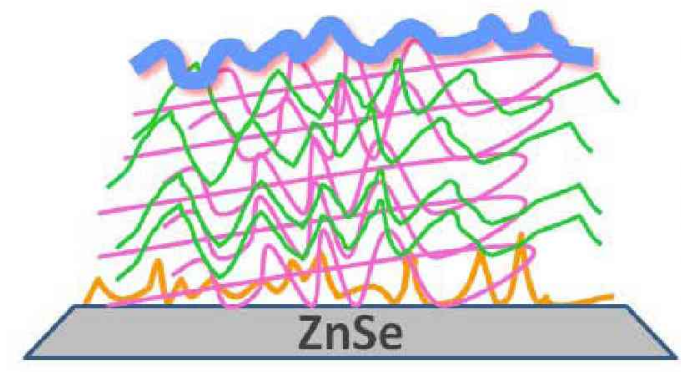

casein

PAH

Figure 2. Model of the polyelectrolyte multilayer on the mica surface used for the AFM studies (A), and on the ZnSe ATR crystal used for the FTIR measurements (B).

\subsection{Protein solutions}

Bovine milk $\alpha$-casein (Sigma, C6780, chromatographically purified, $\alpha_{\mathrm{s}}$-casein minimum 70 $\%$ ) and $\kappa$-casein (Sigma, C0406, minimum 80\% $\kappa$-casein) were purchased in lyophilized form, and were dissolved in $10 \mathrm{mM}$ HEPES buffer at $\mathrm{pH} 7.0$ without any further purification 
(their purity was checked by gel-electrophoresis). The concentration of the casein solution was $0.1 \mathrm{mg} / \mathrm{ml}$ in all experiments. For the FTIR measurements $\mathrm{D}_{2} \mathrm{O}$-based buffer was used.

\subsection{Basic principles and sample preparation for AFM measurements}

The atomic force microscope uses a sharp tip (with a radius of curvature in the order of nanometers) to scan the surface of a sample. This needle is supported on a flexible cantilever. The instrument records the surface topography by detecting the displacement of the cantilever: a laser beam is reflected off the back-side of the cantilever and collected in a four segmented photodiode (Figure 4). A feedback loop connects the photodiode signal with a piezoelectric scanner.

There are two basic types of AFM operations: the contact mode and the intermittent (tapping or AC) mode. In contact mode, by maintaining a constant cantilever deflection (using the feedback loop) the force between the probe and the sample remains constant and an image of the surface is obtained. In AC mode the cantilever is oscillated at its resonant frequency with a few nanometer amplitude. By maintaining a constant oscillation amplitude, a constant tip-sample interaction is maintained and an image of the surface is obtained. In AC operation mode the interaction between the tip and the sample is minimized, therefore it is more suitable for soft biological samples.

In order to investigate a biological sample with AFM, it has to be immobilized on a surface. In all experiments muscovite mica was used for this purpose. The surface of mica after cleavage is hydrophilic, negatively charged and atomically flat (Figures 1 and 3). A $15 \times 15 \mathrm{~mm}^{2}$ mica sheet was freshly cleaved before each experiment. 

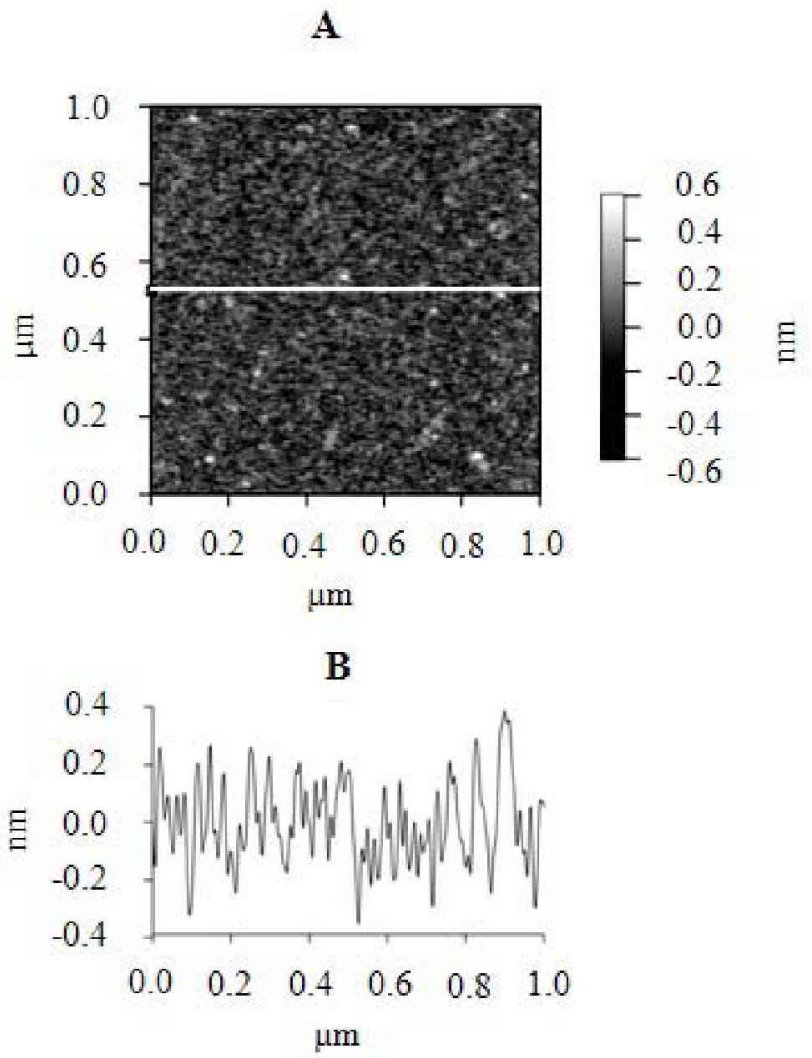

Figure 3. AFM height image of the surface of muscovite mica with distilled water dried onto its surface (A, B).

\subsection{Instrumentation and measuring conditions of AFM studies}

All AFM measurements were performed with an Asylum MFP-3D head and controller (Asylum Research, Santa Barbara, CA, USA). The driver program MFP-3D Xop was written in IGOR Pro Software (version 6.22, Wavematrics, Lake Oswego, OR, USA). The scheme of the instrument is presented on Figure 4. 


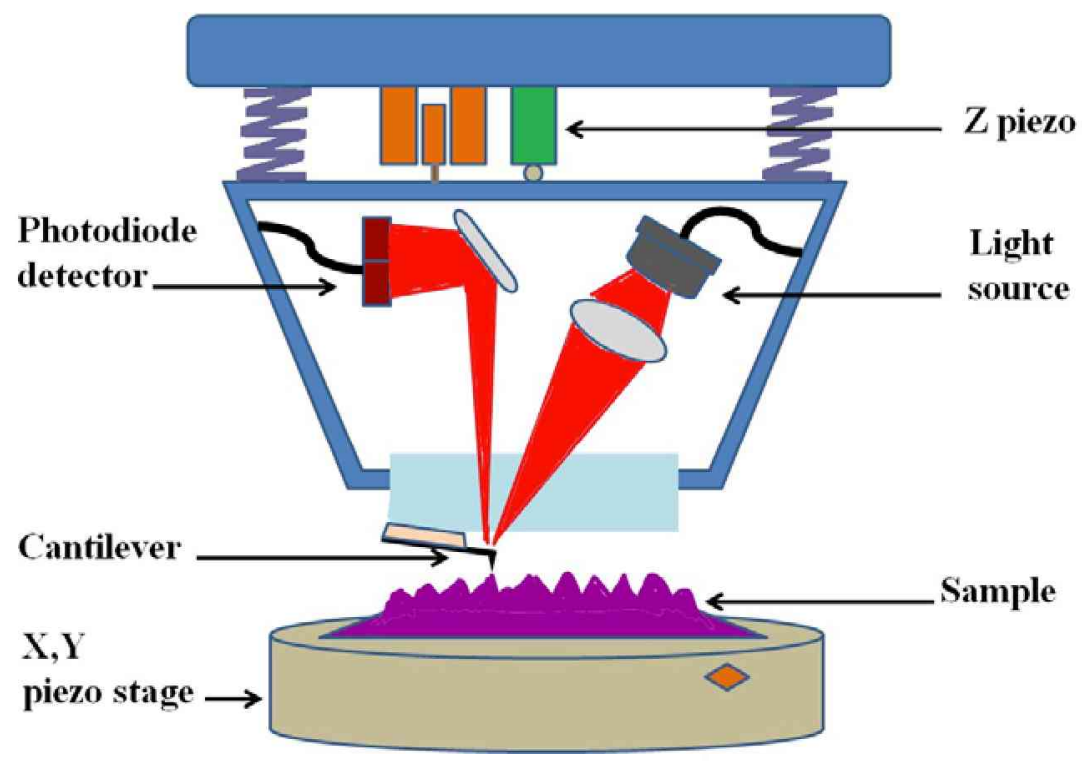

Figure 4. The scheme of the MFP 3D atomic force microscope.

The spring constant for each cantilever was determined by thermal calibration (Hutter and Bechhoefer, 1993; Butt and Jaschke, 1995). The measurements were carried out in ACmode in air or in solution. Typically $512 \times 512$ point scans were taken at a scan rate $1 \mathrm{~Hz}$ per line. Both trace and retrace images were recorded and compared.

For imaging the ODNs AC240 rectangular, Al-coated silicon cantilevers with a tetrahedral tip (Olympus, Optical Co. Ltd. Tokyo, Japan) were used. The nominal properties of these cantilevers are the followings: resonant frequency $70 \mathrm{kHz}$, spring constant $2 \mathrm{~N} / \mathrm{m}$, tip radius $<10 \mathrm{~nm}$. The measurements were carried out in air.

Measurements in solution were carried out using gold-coated, rectangular cantilevers made of silicon nitride with a typical spring constant of $0.03 \mathrm{~N} / \mathrm{m}$, and a V-shaped tip with a tip radius about $30 \mathrm{~nm}$ (BL-RC150 VB-C1: Bio-lever A, Olympus Optical Co. Ltd., Tokyo, Japan).

\subsection{Force measurements and elasticity}

To characterize the changes in the mechanical properties of the protein, the elastic modulus (Young's modulus) was determined by force measurements. The force-displacement curves were recorded with the same cantilever as used for imaging in tapping mode. In the case of the force measurements the tip is engaged at a certain point onto the surface and its deflection 
is monitored in function of the vertical piezo movement. When pushing an absolutely hard surface, there is a linear dependence between the cantilever bending and the applied force (Figure 5A). In case of soft materials the force-distance curve is non-linear. Parameters of the curve can be used to calculate what degree the surface is displaced, when a particular force is applied.

In order to calculate the Young's modulus of the sample only the approaching part of the curves are needed. Calibration and reference curves were taken on hard surface (mica). Subtracting the reference curve from the curves measured on the protein layer gives the indentation, which provides information about the stiffness of the studied material (Figure 5B) (Vinckier and Semenza, 1998).

A

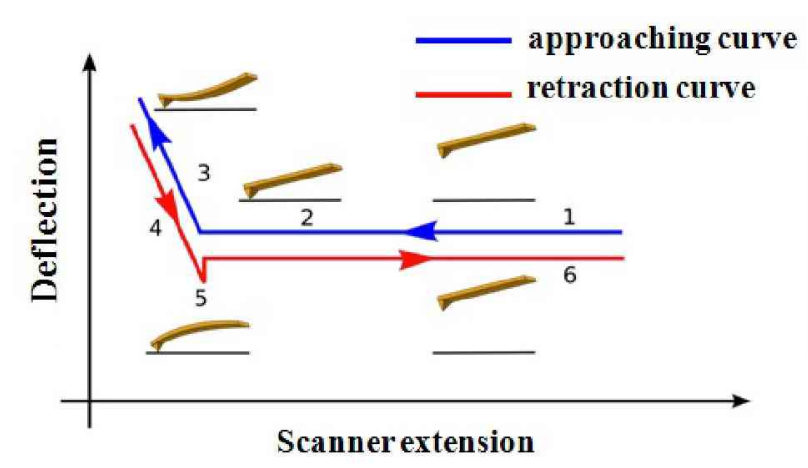

B

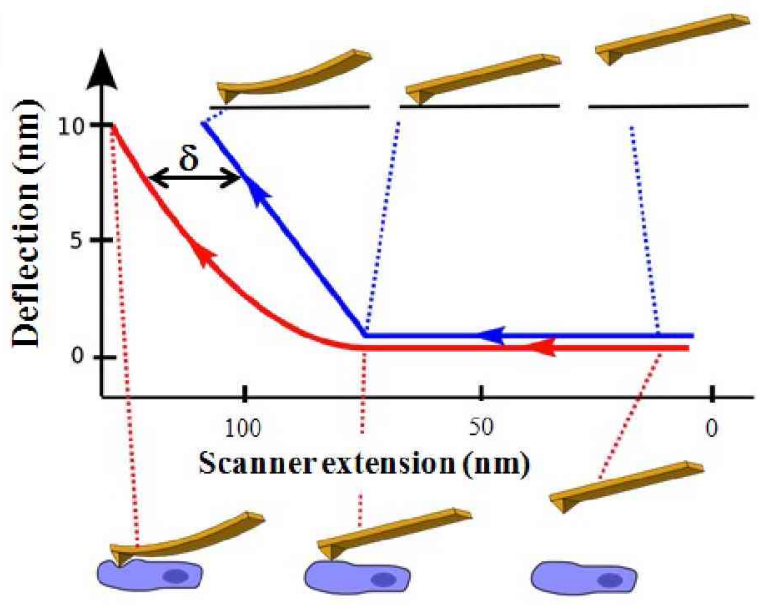

Figure 5. Scheme of characteristic force-distance curves taken on a hard surface (A) and on surfaces with different hardness (B). On 'B' the blue line shows the force curve taken on the mica surface, the red line shows the force curve taken on a softer biological sample. $\delta$ is the indentation.

To obtain the Young's modulus, the theory of Hertz (Hertz, 1881) and Sneddon (Sneddon, 1965) was used, which had been further developed taking into account the different tip forms used for the AFM measurements (Vinckier and Semenza, 1998; Bálint et al., 2007).

The force as a function of the indentation into the sample $(\Delta z)$ for a tip with an opening angle $\alpha$ is given by Equation 1,

$$
F(\Delta z)=\frac{2 E^{*}}{\pi(\operatorname{tg}(\alpha))} \Delta z^{2}
$$


, where $\mathrm{E}^{*}$ is the relative Young's modulus.

The elastic modulus of the sample can be determined if one takes into account the Poisson ratio. Biological samples are generally considered incompressible, so the value of the Poisson ratio is assumed to be 0.5 . Thus, the Young's modulus of the sample $\left(\mathrm{E}_{\text {sample }}\right)$ can be calculated from Equation 2,

$$
\frac{1}{E^{*}} \approx \frac{1-\mu_{\text {sample }}^{2}}{E_{\text {sample }}}
$$

In this case $\mathrm{E}_{\mathrm{sample}}$ is the Young's modulus and $\mu_{\text {sample }}$ is the Poisson ratio of the biological material (Vinckier and Semenza, 1998; Bálint et al., 2007).

\subsection{Attenuated Total Reflection Fourier Transform Infrared (ATR-FTIR) spectroscopy}

These measurements were carried out using a Bruker Vertex70 Fourier transform infrared spectrometer. 2048 interferograms at $2 \mathrm{~cm}^{-1}$ spectral resolution were collected, added, and converted into single beam intensity spectra. As internal reflection element, a trapezoid $\mathrm{ZnSe}$ crystal $\left(45^{\circ}\right.$, six reflection) was used. Inevitably, due to the long duration of the experiments, water vapour bands were appearing in the spectra (in the range of mOD), in spite of the continuous purging of the spectrometer with dry air. These water vapour bands were removed in two steps; first, by interactive vapour spectrum subtraction via the Bruker Opus software, then by an additional de-noising procedure using stationary wavelet transform with the help of Dr. Géza Groma. Other spectrum processing operations were carried out with the SPSERV software (Dr. Csaba Bagyinka, BRC Szeged, Hungary). The changes in the infrared spectra induced by the adsorption steps were evaluated by Singular Value Decomposition (SVD) analysis by one of my co-workers, Dr. Balázs Szalontai.

All FTIR experiments were carried out at room temperature. All casein spectra were recorded in $\mathrm{D}_{2} \mathrm{O}$ environment, therefore Amide I bands will be indicated as Amide I'. The difference absorption spectra of a given layer shown in the figures were calculated by taking always the last single beam spectrum recorded before the adsorption of the layer as background, and the single beam spectrum recorded after the adsorption as sample. 


\section{Results and Discussion}

\subsection{Adsorption and self-assembly of oligonucleotides}

The oligonucleotides (as the building blocks of DNA) are one of the most typical and most important compounds of living organisms. To fulfill their function it is necessary that they have specific self-assembling properties, and as a result of this assembly characteristic structures can be formed. AFM offers a direct way to study these structures on different surfaces.

After drying high purity aqueous solution of ODN (20 nM, pH 4) onto freshly cleaved muscovite mica surface, around $1 \mathrm{~nm}$ high and several hundred $\mathrm{nm}$ long, thread-like formations had been observed (Figure 6).

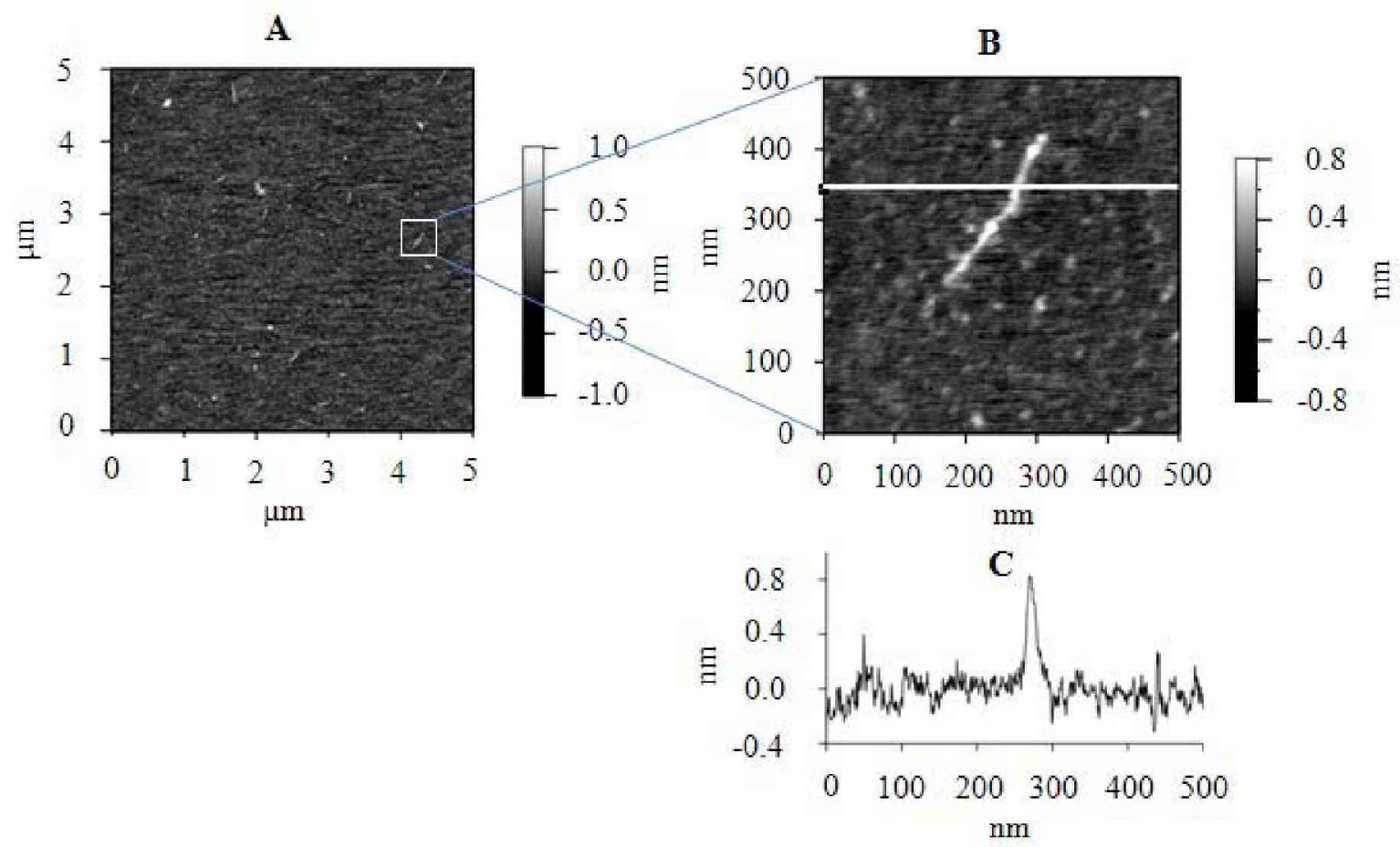

Figure 6. Formation of the oligonucleotide complexes: height images of the surface $(\mathrm{A}, \mathrm{B})$ and the height profile taken along the line (C) after drying $50 \mu \mathrm{l}$ of $20 \mathrm{nM}, \mathrm{pH} 4$ ODN solution on a $15 \times 15 \mathrm{~mm}^{2}$ muscovite mica sheet. 
The high purity of the used materials ensured that the observed formation could only be the ODN self-assembled on the mica surface. A $500 \times 500 \mathrm{~nm}^{2}$ height image of a typical, $200 \mathrm{~nm}$ long structure (B) with its height profile section along the white line (C) is shown on Figure 6. The average height of the observed fibrous structures is of $1.1 \pm 0.3 \mathrm{~nm}$.

In the present work the conditions for self-assembly of ODNs were studied on mica surface. The effect of different physical-chemical parameters (ODN concentration, $\mathrm{pH}$ of the ODN-solution, surface properties) have been tested.

As a control during all experiments, clear water was air-dried under the same conditions onto the mica surface and imaged. The surface roughness of the mica was found to be $0.3 \pm 0.1 \mathrm{~nm}$, and no structures could be observed on it (Figure 3 ).

\subsubsection{The effect of ODN concentration on the self-assembly}

The appearance of the thread-like structures was investigated in function of the ODN concentration. Solutions from 5 to $500 \mathrm{nM}$ of ODN concentrations were prepared and dried onto the mica surface.

At low concentrations (below $7 \mathrm{nM}$ ) mostly small spots appeared on the surface, as the ODN formed small aggregates, containing several oligomers on the mica surface. The threadlike structures started to be observed at around $10 \mathrm{nM}$ concentration (Figure 7A). Increasing the concentration, several $100-200 \mathrm{~nm}$ long strands appeared on a $5 \times 5 \mathrm{~m}^{2}$ mica surface, meanwhile the number of the spots decreased (Figure 7B). At around $20 \mathrm{nM}$ ODN concentration many strands could be observed beside the small spots. As the concentration was further increased, a large number of spots could be identified, but no thread-like formations were observed (Figure 7C). At rather high concentration of ODN, above several hundred $\mathrm{nM}$, large aggregated patches or occasionally a network-like formation appeared on the mica surface (Figure 7D). All these measurements were carried out at $\mathrm{pH} 4$. For explanation of choosing this $\mathrm{pH}$ value see section 4.1.2. 
A
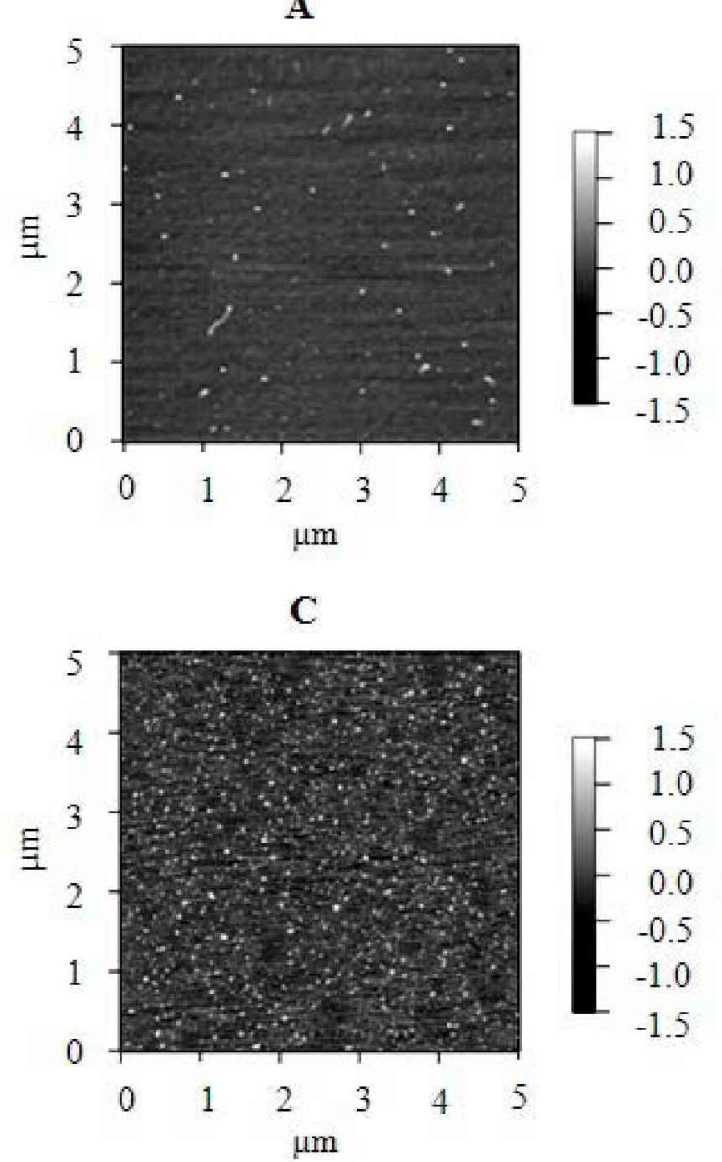
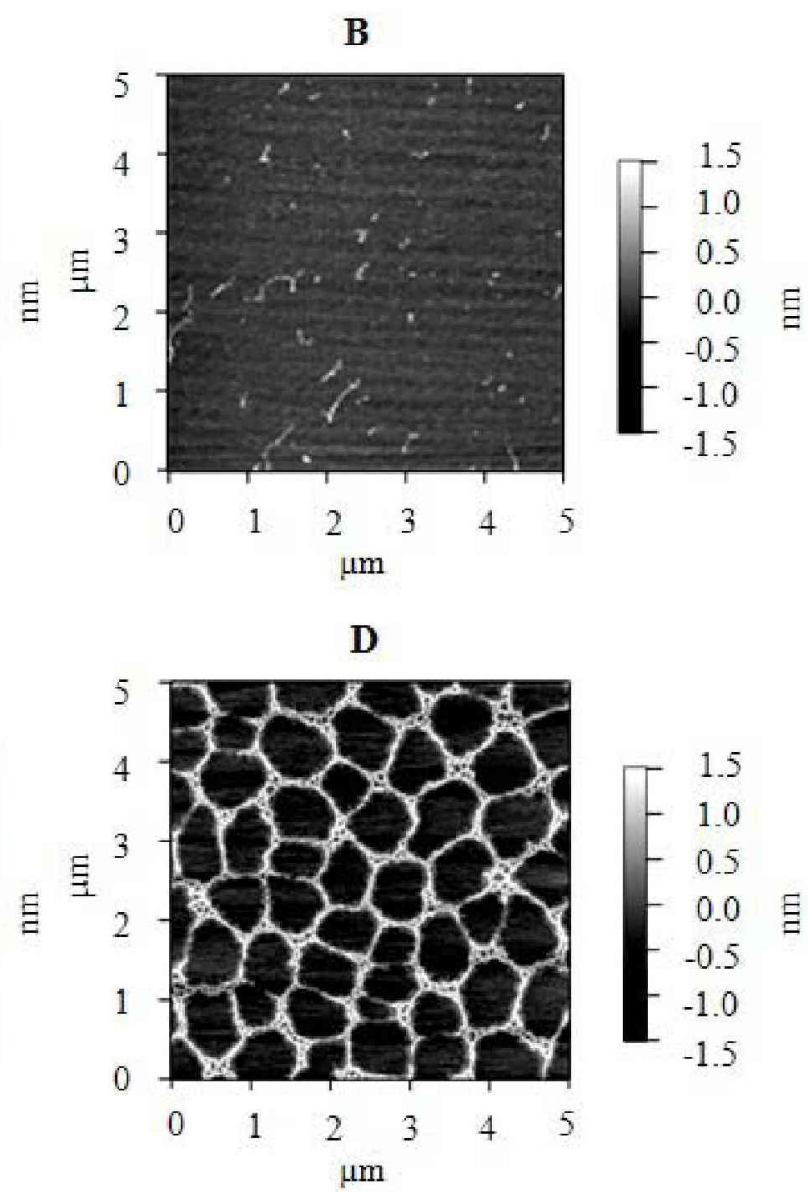

Figure 7. Structures of ODN on mica surface when different concentrations of $50 \mu$ of ODN solutions were dried on a $15 \times 15 \mathrm{~mm}^{2}$ surfaces: $10 \mathrm{nM}$ (A), $20 \mathrm{nM}$ (B), $40 \mathrm{nM}$ (C) and $400 \mathrm{nM}$ (D).

According to these measurements we found the $20 \mathrm{nM}$ initial ODN-concentration to be the best for the appearance of the few hundred nanometer long thread-like structures on the mica surface. Within these conditions sometimes even longer and more complex formations could be observed, like on Figure 8, where we can see a "serpentine nest" formation. The height profile (Figure $8 \mathrm{~B}$ ) shows that even in this case the height of the individual filaments are in the range of $1.1 \pm 0.3 \mathrm{~nm}$, which is in good agreement with previous experiences. Figure $8 \mathrm{C}$ is the $3 \mathrm{D}$ representation of the height image of the "serpentine nest". 

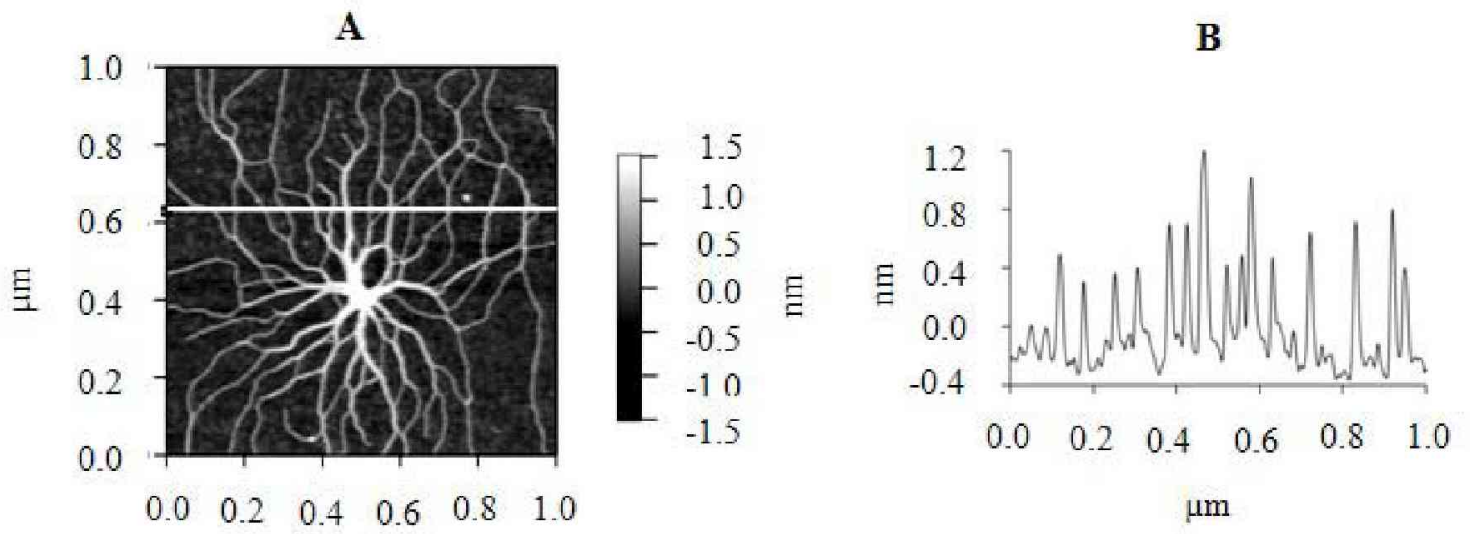

$\mu \mathrm{m}$

$\mathrm{C}$

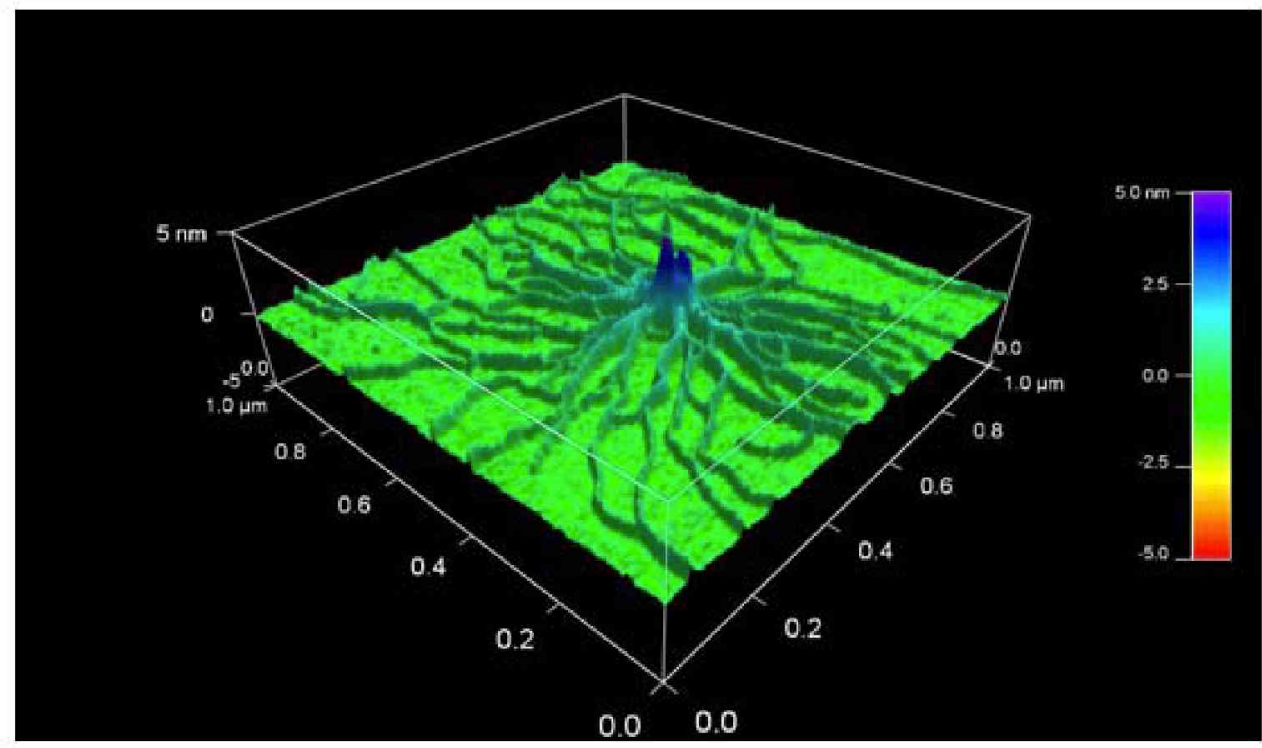

Figure 8. Formation of complex oligonucleotide structures on the surface: $1 \times 1 \mu \mathrm{m}^{2}$ height image and the corresponding height profile (A, B) after drying $20 \mathrm{nM}$ solution on the muscovite mica surface, and the 3D image of it (C).

The average number of oligonucleotides participating in the formation of these threadlike structures can be estimated by a simple calculation. For this calculation the characteristic parameters of the individual nucleotides were taken from the literature: the length of one single nucleotide is considered to be $0.34 \mathrm{~nm}$ and its width is $1 \mathrm{~nm}$. Using these parameters the size of our ODN that consists of 18 nucleotides can be estimated as $1 \mathrm{~nm} \times 1 \mathrm{~nm} \times 6 \mathrm{~nm}$. According to this calculation a typical $200 \mathrm{~nm}$ long structure contains at least 30 ODNs. 
By this estimation we get information only about the minimum number of the connected oligonucleotides but we still don't know how the molecules are connected. Unfortunately, from the AFM images we can't figure out whether the molecules stick together by end to end or there are overlapping regions where some midsegments bind to each other.

The geometry of the AFM tip gives some limitations to the lateral resolution: the width of the observed structure always looks bigger on the images than really it is. This problem is well-known in the literature. Paquim and his coworkers have discussed this problem in their paper about studying oligonucleotides on the surface of HOPG (Paquim et al., 2006). Taking into account that the radius of the AFM tip is around $10 \mathrm{~nm}$, the real width of the thread-like formations is between 2 to $8 \mathrm{~nm}$, and the height of them is $1 \mathrm{~nm}$. Considering the size of the ODN as mentioned above (about two to eight molecules could form the cross-section), a total of several hundred molecules are condensed in a typical thread-like formation like on Figure 9.

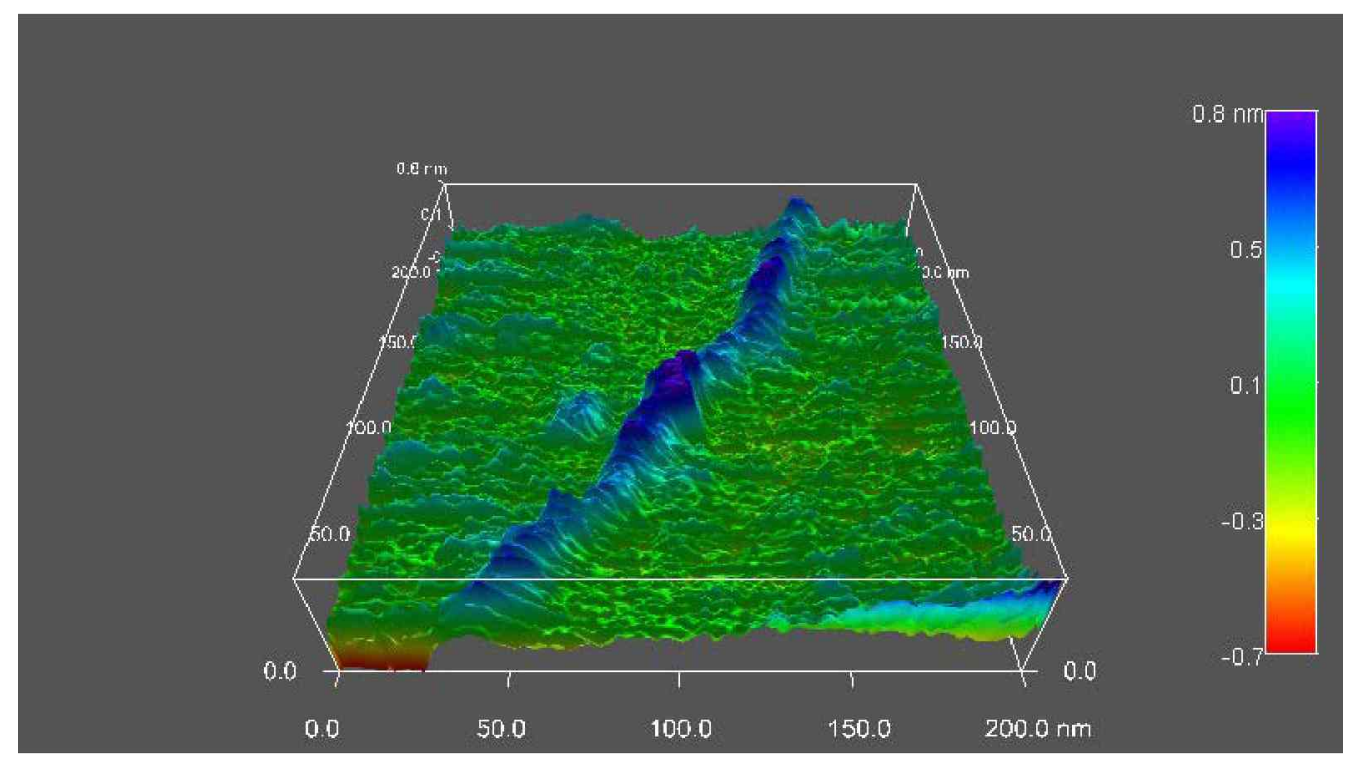

Figure 9. 3D image of a typical ODN complex after drying $20 \mathrm{nM}$ ODN-solution (pH 4) onto muscovite mica surface. 


\subsubsection{The effect of $\mathrm{pH}$ on the ODN structures}

The next parameter to control was the $\mathrm{pH}$ of the initial ODN solution. For these experiments, $20 \mathrm{nM}$ ODN was used, which proved to be optimal to obtain the thread-like formations on the surface. The $\mathrm{pH}$ could have a double effect on the appearing structures. On one hand, it can influence the distribution of the charges on the surface, on the other hand, the protonation of the acidic/basic groups of the ODN also depends on it.

The $\mathrm{pH}$ was set by dropping a predetermined quantity of $100 \mathrm{nM} \mathrm{HCl}$ in the solution, to get the desired acid concentration. After the sample was spread onto the freshly cleaved mica surface, the $\mathrm{pH}$ of the remaining solution was measured and considered as the $\mathrm{pH}$ of the sample.

Figure 10 represents characteristic high resolution images taken of ODN-solutions with different $\mathrm{pH}$ dried on the surface of muscovite mica. The optimal $\mathrm{pH}$ for the appearance of the thread-like formations fell in a narrow acidic range, between $\mathrm{pH} 3.4$ and $\mathrm{pH} 4$. The average number of these filamentous structures was the highest at $\mathrm{pH} 4$. Drying a $20 \mathrm{nM}$ ODNsolution at $\mathrm{pH} 4$, an average of 20 thread-like formations appeared on a $25 \times 25 \mathrm{~m}^{2}$ image. At pH 3.7 and pH 3.4 this value was 5 and 9 on the same area. Below pH 3.4 and above $\mathrm{pH} 4.0$, no such structures had been observed, the surface was covered by small spots and aggregates (Figure 10A,D,E).

Our findings about the importance of the $\mathrm{pH}$ of the initial ODN-solution is in good agreement with the observations of Allemand and coworkers. They could bind DNA molecules to different surfaces by optimizing the $\mathrm{pH}$ of the solution. Only at certain $\mathrm{pH}$ values they could reach the specific interaction between the molecules and the surface (Allemand et al., 1997). 

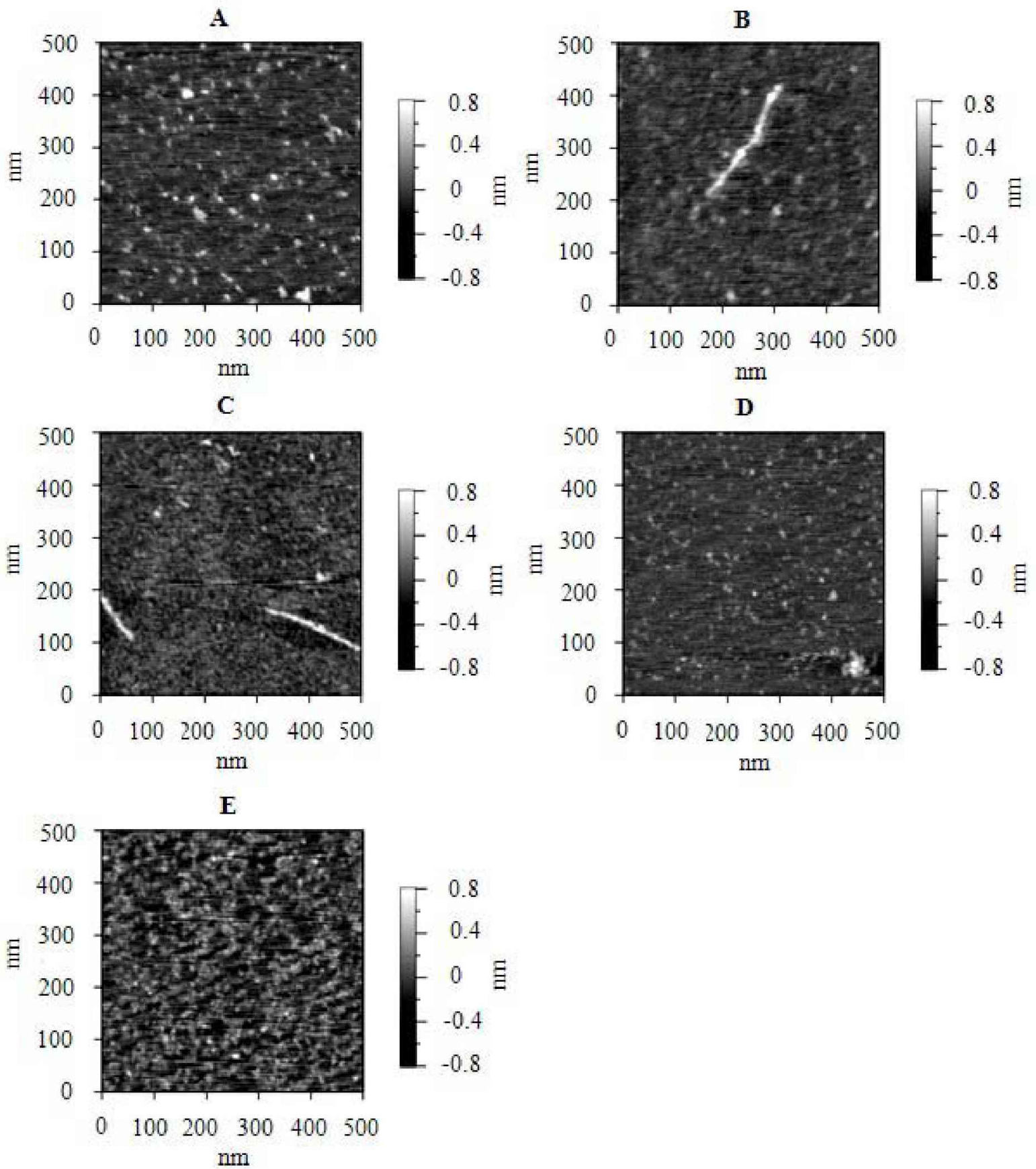

Figure 10. The effect of $\mathrm{pH}$ on the ODN structures, when $50 \mu$ solutions $(20 \mathrm{nM})$ were dried on a $15 \times 15 \mathrm{~mm}^{2}$ surfaces: $\mathrm{pH} 5$ (A), pH 4.0 (B), $\mathrm{pH} 3.4$ (C), pH 3.2 (D) and pH 3.0 (E). 


\subsubsection{The influence of different surfaces on the structures}

To investigate the influence of the chemical composition of the surface on the thread-like formations, some other surfaces were tested beside muscovite mica, such as HOPG, n-type silicon and glass. The experiments were performed under optimal conditions determined before (20 nM ODN at $\mathrm{pH} 4)$. The AFM images with the height profiles can be seen on Figure 11 .

The mica, with its chemical composition of $\mathrm{K}_{2} \mathrm{Al}_{4} \mathrm{Si}_{6} \mathrm{Al}_{2} \mathrm{O}_{20}(\mathrm{~F}, \mathrm{OH})_{4}$, has a monoclinic crystalline structure, with $2 / \mathrm{m}$ symmetry. The cleavage surface is characterized by partially delocalized negative charges in combination of weakly bound, localized positive charges of $\mathrm{K}^{+}$-ions (Berry et al., 1983). During the drying process, these weakly localized positive charges could be the targets for the partially negatively charged ODN, resulting in the threadlike structures (Figure 11A,B).

The HOPG has a hexagonal crystalline structure (Berry et al., 1983). These lamellar crystals have perfect cleavage in one direction, similar to the mica. An important difference between the two surfaces is that after cleavage, no free charges appear on the HOPG surface. Observing dried ODN on the HOPG surface was not successful because the surface is strongly hydrophobic and the ODNs were probably localized on the edges of different cleavage planes. By AFM, only the small lamellar surfaces were visualized, with no ODN on them (Figure 11C,D).

The n-type silicon surface is crystalline with face-centered cubic symmetry. It has strongly delocalized negative charges in the conduction band. The surface was polished in the (100) plane. After drying ODN solution under the optimal conditions, only small aggregation spots appeared on the surface, but no thread like formations (Figure 11E,F).

As an amorphous surface, a microscope glass-slide was also used for ODN deposition. As it can be seen from Figure 11, this surface was not smooth enough for imaging the macromolecules. While the roughness of mica and silicon is below $1 \mathrm{~nm}$, the glass-slide contains several $\mathrm{nm}$ high protrusions $(3 \pm 1 \mathrm{~nm})$. With this roughness, it is hard to totally exclude the formation of ODN structures during the drying process, but the obtained images make it very unlikely (Figure $11 \mathrm{G}, \mathrm{H}$ ). 
A
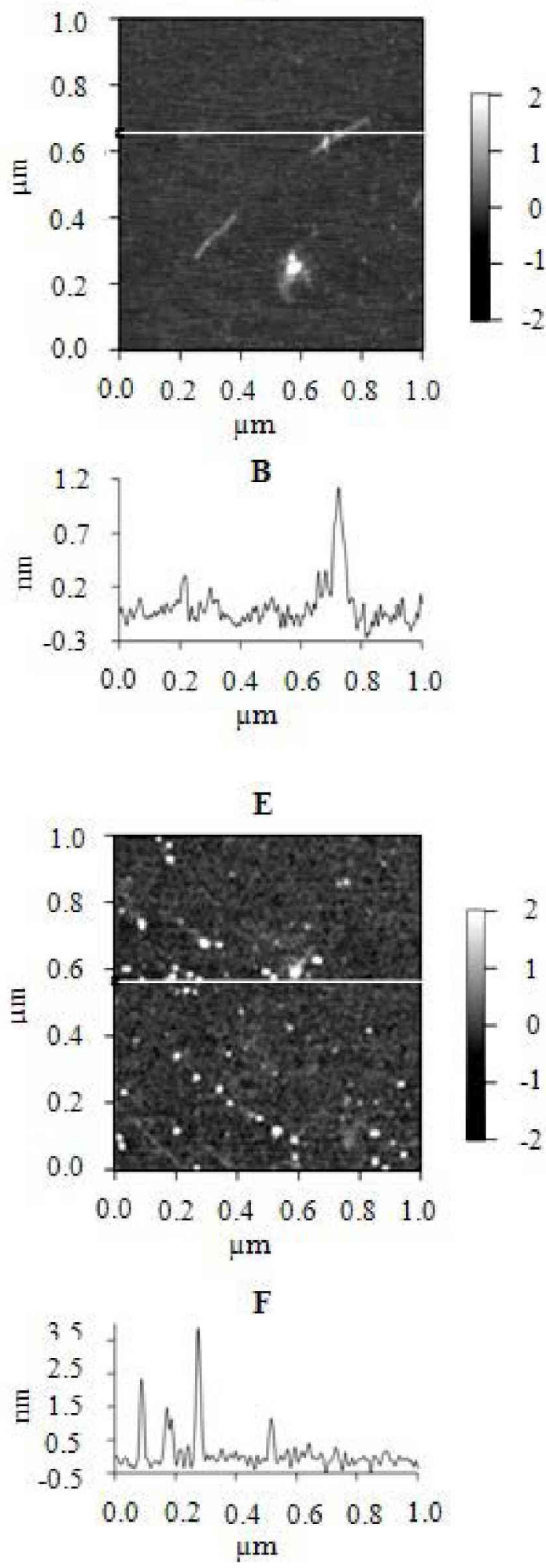
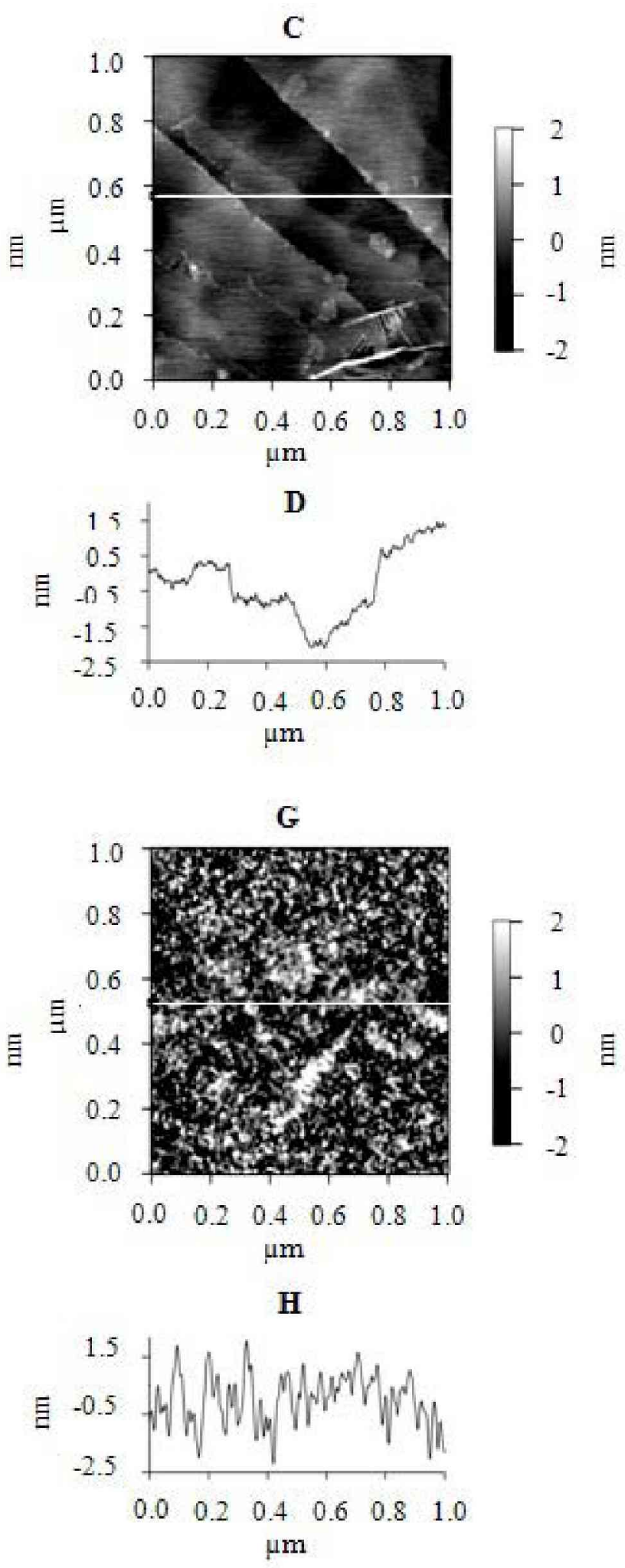

Figure 11. The height images and height profiles of different surfaces with $50 \mu$ ODN solutions (20 nM, pH 4) dried on it: mica (A, B), HOPG (C, D), silica (E, F), glass cover slide (G, H). 


\subsubsection{Conclusions on oligonucleotides}

Summing our observations, self-assembly of surface dried oligonucleotides on mica surface could be monitored by AFM. This assembly seems to be conditioned by the presence of the localized positive charges on a smooth crystalline surface. These charges can interact with the strongly negatively charged ODNs to deposit in ordered structures. At high $\mathrm{pH}$ and large ODN concentration the interaction is quite strong, and aggregation of ODNs occurs. By decreasing the $\mathrm{pH}$ and/or the ODN concentration to an optimal value, probably the end part of the ODN remains more active (Allemand et al., 1997), promoting the thread-like formations.

The composition of the mica is very similar to that of montmorillonite clay. Both minerals belong to the muscovite family having the main composition of silicate aluminum oxide, containing mono- or divalent cations such as $\mathrm{K}^{+}, \mathrm{Na}^{+}$, or $\mathrm{Ca}^{2+}$-ions. The partially titrated positive and negative charges on the mica and/or the ODN respectively interact in an oriented way. Based on this observation, the theory of the origin of the information coding DNA and RNA related to the montmorillonite clay may be generalized to the muscovite mica as well.

This part of the work was published in the Journal of Physical Chemistry $C$ (see Publication List No. I.) 


\subsection{Step-by-step built of casein aggregates on charged polyelectrolyte film surfaces}

The sequential adsorption of polyions is an effective tool in nanotechnology for creating welldefined multilayers (Decher, 1997). The interaction of such multilayers with biological materials, such as proteins can result in several practical applications. Casein is a phosphoprotein that found in micellar form in mammalian milk. Its function is to store and transport calciumions. This protein has a strong tendency to self-associate, but our knowledge about the adsorption and aggregation properties of caseins is limited. Thanks to its calciumand phosphate-binding ability, multilayers containing casein can be used in biotechnology and in medical applications also. Therefore it is important to understand the aggregation properties of this family of proteins.

We have studied the possible mechanism of casein aggregation and micelle build-up with a method, which has never been applied before, by letting $\alpha$-casein adsorb onto positively or negatively charged surfaces of polyelectrolyte films from low-concentration $(0.1 . \mathrm{mg} / \mathrm{ml})$ solutions. The structural properties of the film and the planar protein layer were studied by AFM and FTIR spectroscopy. The topography and the stiffness/hardness of the multilayer can be studied by AFM, while FTIR gives us information about the secondary structure of the adsorbed protein.

The charged surface, giving the possibility of the adsorption of casein onto the surface of the ATR crystal or mica, was a 'layer-by-layer' polyelectrolyte film, built according to the method of Decher from PSS and PAH. The details about the preparation of the film are discussed in the Materials and Methods (Figure 4). With this approach, an $\alpha$-casein monolayer was formed. We studied the conditions under which calcium-phosphate nanoclusters $(\mathrm{CaP})$ can be incorporated, and further casein layers added (Nagy et al., 2010; Nagy et al., 2012).

When creating a polyelectrolyte multilayer, it is a widely used method to cover the hard surface with an initial layer of PEI electrolyte, and we used it as well for the ZnSe ATR crystal. AFM surface topography showed that the presence of PEI on the mica surface causes a higher roughness for the final film, large aggregates could be observed on the height images (Figure 12). To achieve a smooth surface (roughness of $3 \pm 1 \mathrm{~nm}$ ), where we could follow the morphological changes, we avoided using PEI as initial layer on the mica surface. The muscovite mica with its hydrophilic, negatively charged surface is convenient for the 
adsorption of PAH polycations as the first layer of the film. Even in future biological applications it could be useful to avoid using PEI because of its toxicity.

Before each series of AFM experiments the topographic image of the polyelectrolyte film had been recorded as a control before the protein layer was let to adsorb on its surface. These images ensured us that the polyelectrolytes covered the whole surface of mica, and there are not too many inhomogeneities in its pattern (Figure 12C and Figure 14A).

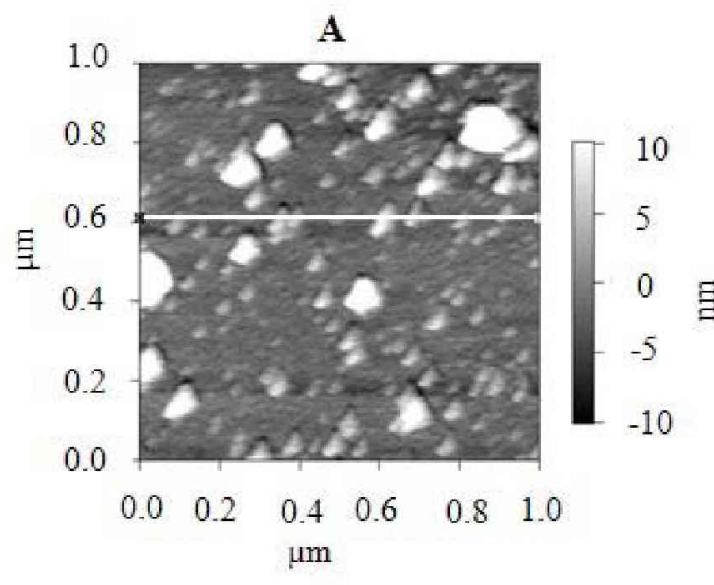

B

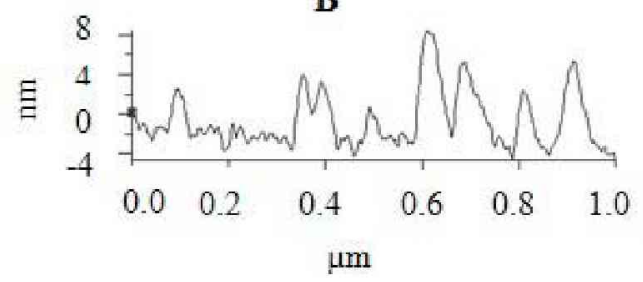

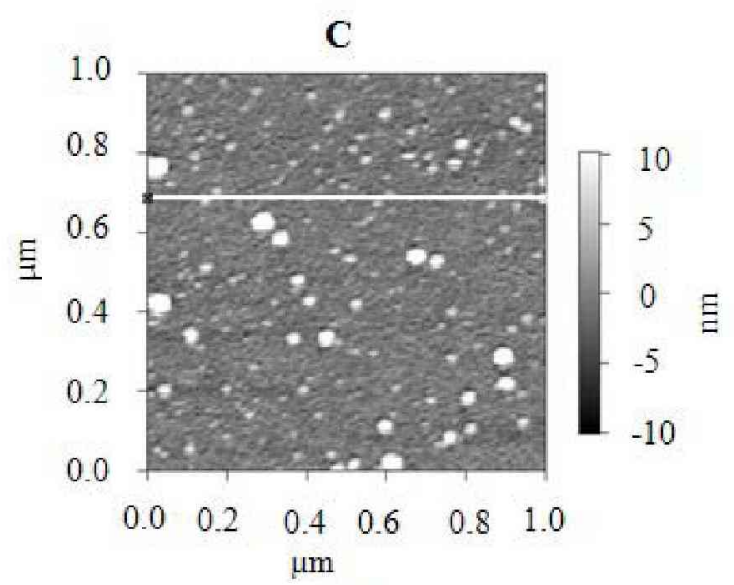

D

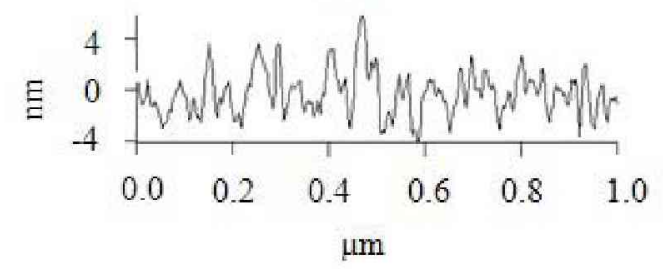

Figure 12. Height images and profiles of (PAH/PSS $)_{6}$ multilayers using a PEI as first layer: PEI$(\text { PSS-PAH })_{5}$-PSS $(\mathrm{A}, \mathrm{B})$ and without PEI as initial layer: $(\mathrm{PAH}-\mathrm{PSS})_{6}(\mathrm{C}, \mathrm{D})$.

In our first experiments we had to check whether casein was able to adsorb on polyelectrolyte multilayers. Its adsorption was followed by infrared spectroscopy. After that the calcium- and the phosphate-binding properties of the adsorbed casein were tested.

\subsubsection{Casein adsorption onto positively or negatively charged polyelectrolyte surfaces}

Since casein has a net negative charge due to its phosphoseryl residues, it is expected to adsorb onto positively charged surfaces, like PAH. Indeed when it was left to adsorb onto the positively charged surface of a PEI-(PSS/PAH) 6 polyelectrolyte film, according to the 
measured infrared spectra (Amide I'. band) a large amount of protein could adsorb onto the surface. However, this adsorbed protein later resisted any further manipulation, no calcium- or phosphate-ions could adsorb onto it.

Surprisingly, when a PEI-(PSS/PAH) 5 -PSS polyelectrolyte film, which has a negatively charged surface, was used, there was also casein adsorption (Figure 13, curve casein-I), and this casein layer could be manipulated. Calcium- and phosphate-ions could bind, and multilayered casein architectures could be built up (Figure 13). Therefore, we dealt only with caseins adsorbed onto the PSS-terminated polyelectrolyte film.

\subsubsection{Aggregation of $\alpha$-casein in the presence of $\mathrm{CaP}$ nanoclusters (PSS-terminated films)}

As the first step, calcium-phosphate nanoclusters were formed on the protein surface by circulating high concentration of $\mathrm{Ca}^{2+}$-ions in the form of $1 \mathrm{M} \mathrm{CaCl}_{2}$. Then, without washing away the Ca-solution, the solution of $50 \mathrm{mM} \mathrm{Na}_{2} \mathrm{HPO}_{4}$ was introduced into the sample holder by a peristaltic pump. As the evidence of this treatment a huge phosphate band appeared on the infrared spectrum at the $1200-1000 \mathrm{~cm}^{-1}$ region (Figure 13 , curve CaP I.). As it can be seen on Figure 13, repeating these treatments consecutive layers of $\alpha$-caseins could be built up (Figure 13, curves casein I-III.).

If a second layer of $\alpha$-casein was let to adsorb onto the CaP-enriched first casein layer, a large increase in the Amide I' region of the infrared absorption spectrum can be observed (Figure 13, curve casein I-II.) together with certain loss of the $\mathrm{CaP}$. Adding $\mathrm{CaP}$ to the second casein layer, the further increase of the phosphate bands appears on the spectrum (Figure 13, curve CaP II.). 


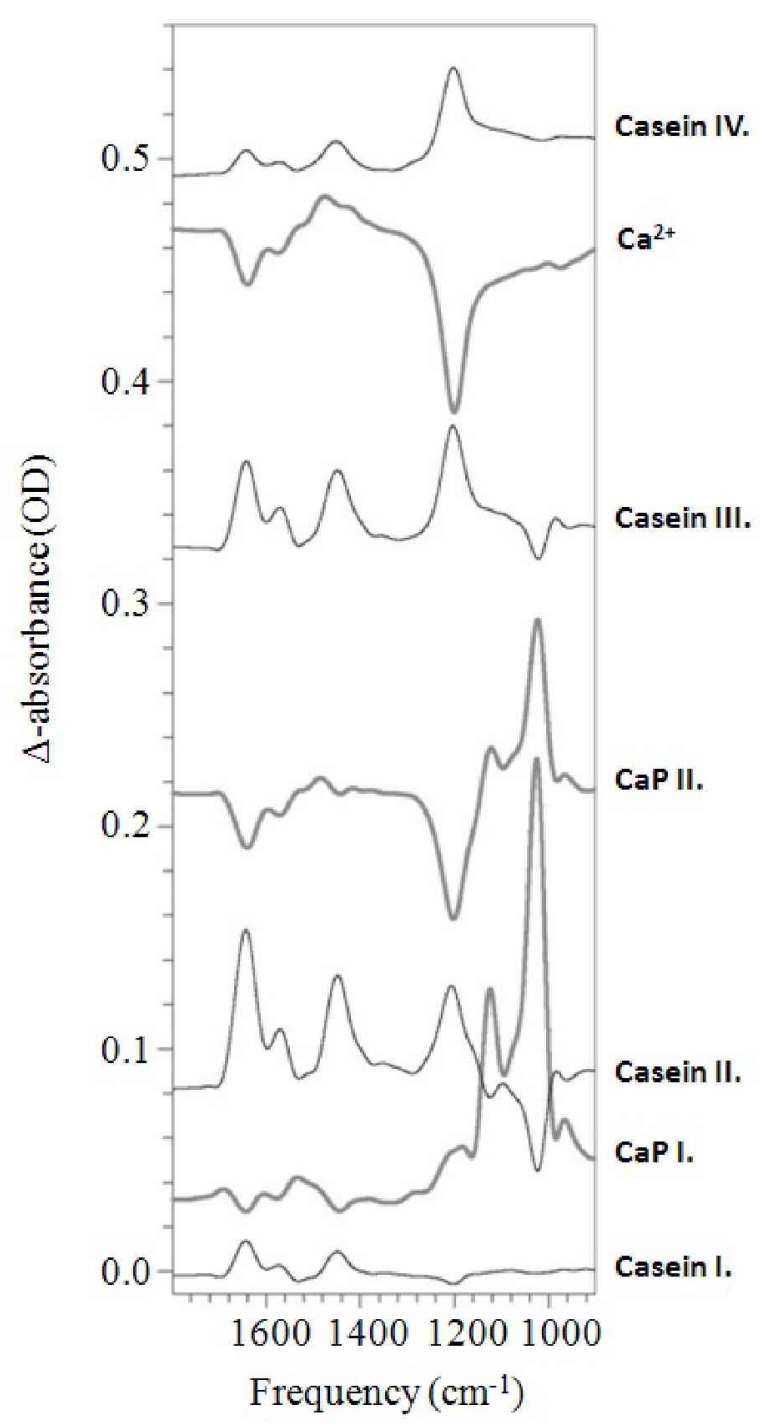

Figure 13. Increments of the infrared absorption upon the buildup of casein multilayers on the surface of an ATR crystal.

The ATR-FTIR measurements proved that the casein layer on the surface of negatively charged polyelectrolyte film preserves its ability to bind calcium- and phosphate-ions. The increments of the Amide I' regions indicate the increasing amounts of adsorbed protein in case of $\mathrm{CaP}$ formed on the previous layer.

To characterize the morphological and elastic changes in the constructed multilayers atomic force microscopy studies have been carried out at each step of the manipulation. Figure 14 shows height images of three distinct steps of one set of experiments: the surface of the pure polyelectrolyte film (A), the adsorbed protein layer (B), and the $\alpha_{s}$-casein surface, after the treatment with solutions of calcium- and phosphate-ions (C). The curves on 
Figure 14 show the height profiles obtained along the white horizontal lines of the corresponding height images. Both the native and the CaP-treated casein exhibit sphere-like features, whose diameter is in the range of a few tens of nanometres. The size of these spheres is in good agreement with those found earlier on spin-coated casein films (Müller-Buschbaum et al., 2007).

By visual inspection, these spheres seem to be smaller and more densely packed in the CaP-treated casein film. The roughness of our casein films calculated from the AFM topography data was somewhat larger for the pure casein $(5.94 \pm 2.66 \mathrm{~nm})$ than for the CaPtreated one $(3.46 \pm 1.73 \mathrm{~nm})$. (These values are averages of five independent experiments on different mica surfaces with different films.)

A
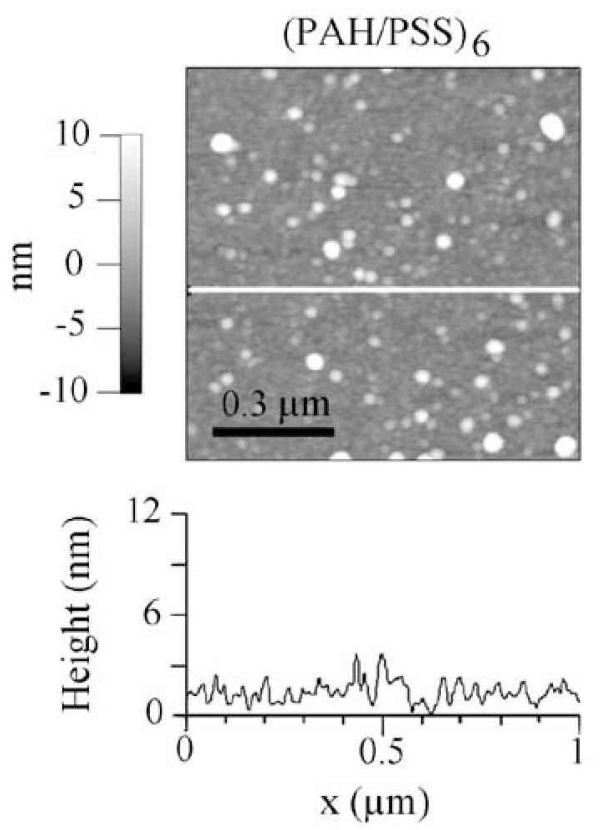

B
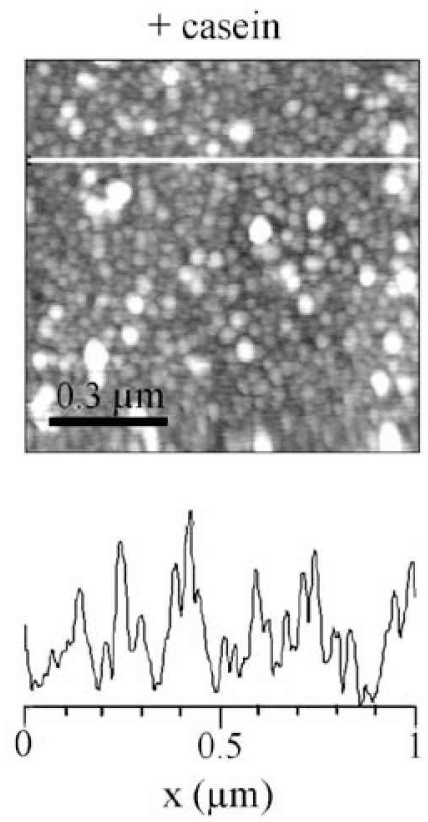

$\mathrm{C}$
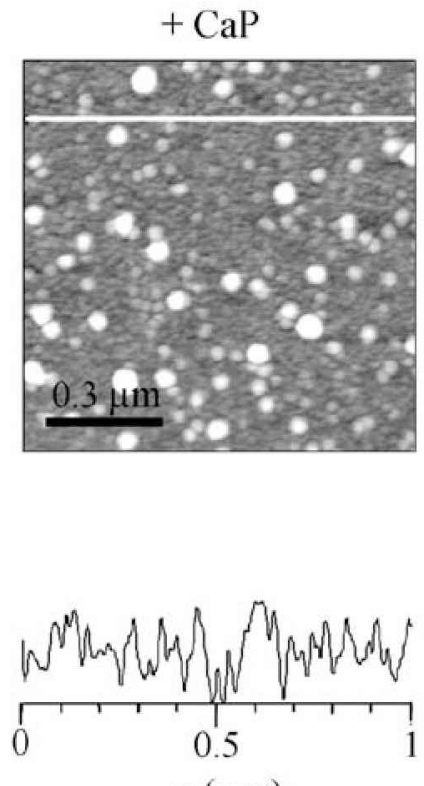

Figure 14. $1 \mathrm{x} 1 \mu \mathrm{m}$ AFM height images of a (PAH/PSS) 6 polyelectrolyte film (A), the surface of casein adsorbed onto the film (B), and the same casein surface after $\mathrm{CaP}$ incorporation (C). The traces below the images represent height profiles recorded along the white lines of the corresponding images.

To reveal the changes in the mechanical properties of the protein, the elastic (Young's) modulus was determined by force measurements. The force-indentation curves on Figure 15 give us information about the stiffness changes during each step of the experiment. 


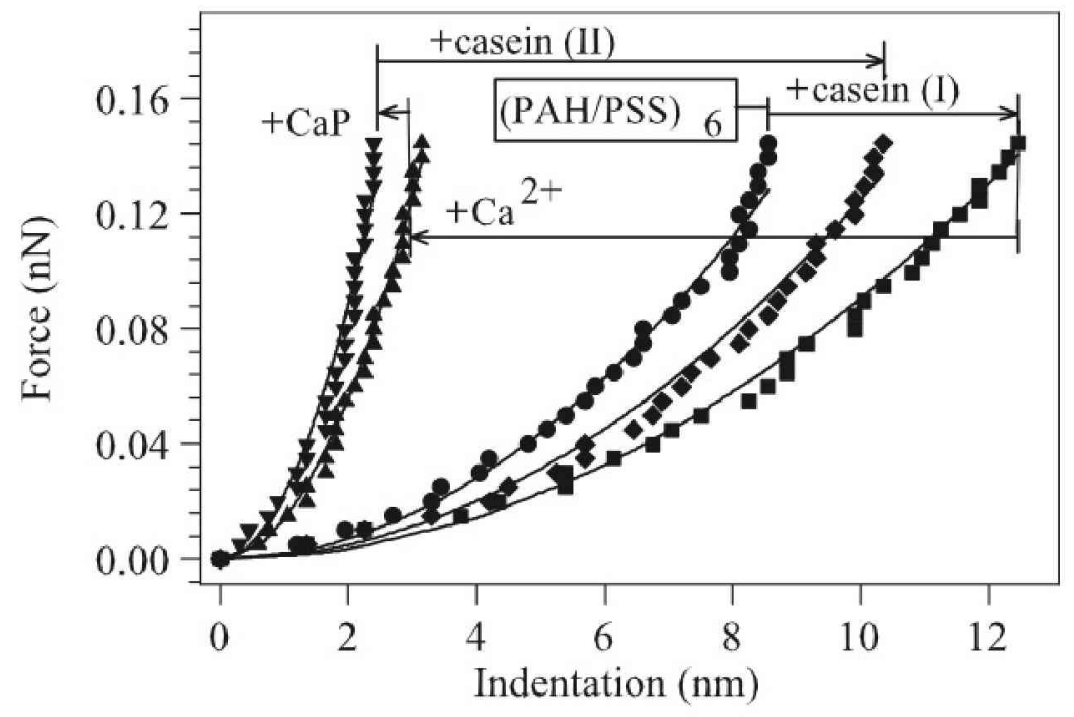

Figure 15. Force curves of the cantilever indentations during a characteristic experiment when different film architectures were built consecutively as follows: - (PAH/PSS $)_{6}$ polyelectrolyte film; - $-(\mathrm{PAH} / \mathrm{PSS})_{6}+$ casein on the polyelectrolyte film; $\boldsymbol{\Delta}-(\mathrm{PAH} / \mathrm{PSS})_{6}+$ casein $+\mathrm{Ca}^{2+} ; \boldsymbol{\nabla}-$ $(\mathrm{PAH} / \mathrm{PSS})_{6}+$ casein $+\mathrm{CaP}$ nanoclusters; $\bullet-(\mathrm{PAH} / \mathrm{PSS})_{6}+$ casein with CaP nanoclusters + second 'pure' casein.

Before each experiment the cantilever was calibrated and reference curves were taken on hard surface (mica). Subtracting the reference curve from the curves measured on the multilayer gives the indentation, which provides information about the stiffness of the studied material. The details of the elasticity measurments are written in the Materials and Methods part of the thesis (Figure 5).

The force curves taken at each step of the experiments confirmed our observation that the calcium-treated surface became more 'compact'. On Figure 15 arrows indicate the 'circle' of the stiffness changes as one series of measurements starting from the relatively stiff, densely packed (PAH/PSS) 6 film. The adsorbed casein is much softer. Adding $1 \mathrm{M} \mathrm{CaCl} 2$ dramatically hardens the film (about ten-fold). In the presence of $\mathrm{CaP}$ nanoclusters the stiffness didn't change a lot. If a second layer of casein was adsorbed onto the CaP-clustered first layer, the film became much softer again.

Control measurments had been carried out by investigating the effect of $50 \mathrm{mM}$ $\mathrm{Na}_{2} \mathrm{HPO}_{4}$ solution itself, without the calcium-treatment. In this case no structural and morphological changes could be revealed by AFM. The phosphate-ions themselves can not alter the structure of the protein layer. We also checked the hardening effect of the $\mathrm{Ca}^{2+}$ - 
treatment on the (PAH/PSS) 6 film itself and its largest change in the Young's moduli was only two-fold. Thus, the more than ten-fold hardening effect of the $\mathrm{Ca}^{2+}$-treatment in caseins can be safely assigned to the $\mathrm{Ca}^{2+}$-altered casein structure.

By using our multilayered model system, it was found that the $\alpha$-casein preserves its calcium- and phosphate-binding ability in case of adsorption onto a negatively charged surface. For the $\mathrm{CaP}$ incorporation and the build-up of the casein multilayers, it is important that the protein first has to bind the calciumions, and only after that can interact with the phosphate ions. We have showen that from $\alpha$-casein, aggregates - similar to natural casein micelles - can be built up step-by-step if calcium-phosphate nanocluster incorporation is ensured between the protein-adsorption steps. It remained, however, an open question, whether the growth of the aggregates can be terminated, similarly as it happens in nature with the casein micelles.

\subsubsection{Aggregation of $\mathrm{K}$-casein in the presence of $\mathrm{CaP}$ nanoclusters (PSS-terminated films)}

According to all existing models of the casein micelle (CM) build up, the Ca-sensitive $\alpha$ - and $\beta$-caseins are located in the interiors, while the Ca-insensitive $\kappa$-caseins are at the surfaces of the micelles (Horne, 2002; Farrell et al., 2006; Qi, 2007). The presence of к-casein at the outer part of the CM-s should be important from the stability point of view, and all the models suggest a key-role of $\mathrm{k}$-casein in termination of the micelle build-up. Therefore, the aggregation of $\kappa$-caseins has also been tested applying similar conditions that we used above, with the $\alpha$-casein.

К-casein showed similar adsorption properties to the polyelectrolyte multilayer as we observed in case of $\alpha$-casein. The lower panel of Figure 16 represent the Amid I' band of the recorded absorption spectra (Figure 16, curve k-casein). Calcium- and phosphate-ions could also bind, and multilayered casein architectures could be built up.

If the consecutive protein layers were intercalated by a CaP nanocluster forming step, the amounts of the adsorbed $\alpha$-, and $\kappa$-caseins were similar, and the construction of the protein multilayer could go on, apparently unlimited. Figure 16 shows the increments in the Amide I' region adsorbing more and more protein to the surface (Figure 16). 


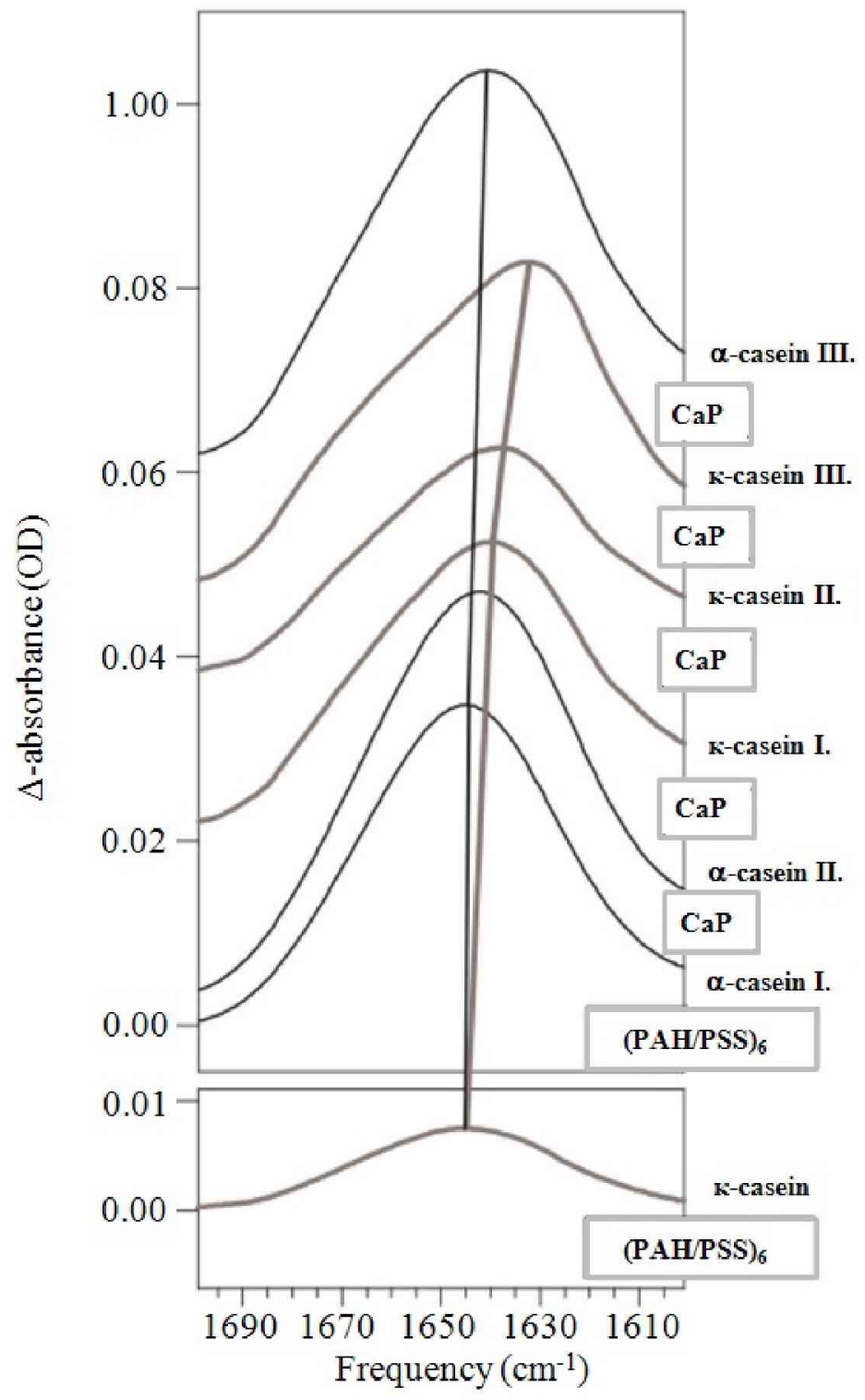

Figure16. Amide I' absorption increments upon $\alpha$ - or $\kappa$-casein adsorption steps interlaced by intermediate $\mathrm{CaP}$ nanocluster formation. The lower panel shows the Amide I' region of $\kappa$-casein from a separate experiment on the surface of PEI-(PSS/PAH) $)_{5}$-PSS polyelectrolyte film.

Comparing the shape of the curves, the Amid I' band of the adsorbed $\alpha$ - and к-casein looks similar, however the frequency of its maximum is downshifted in the case of k-casein. When $\alpha$-casein is put on the top of $\kappa$-casein, there is no further downshift; instead, the frequency of the Amide I' band of the latest adsorbed $\alpha$-casein is again very close to that of the first $\alpha$ casein layer (Figure 16). This downshift refers to the appearance of $\beta$-structures (Arrondo et al., 1993). 


\subsection{4. к-casein adsorption onto $\alpha$-casein without $\mathrm{CaP}$ nanoclusters}

To terminate the micelle build-up, $\kappa$-casein should be able to adsorb onto $a$-casein even without the presence of $\mathrm{CaP}$ nanoclusters. (We found that in the case of $\mathrm{CaP}$ incorporation the protein adsorption could go on endless.) We have done a series of experiments to check this hypothesis. ATR-FTIR absorption spectra were used to prove the presence of the adsorbed protein (Figure 17), the morphological and elastic properties of the created multilayers were studied by AFM (Figures 18 and 19).

As a control, two $\alpha$-casein layers were put onto the polyelectrolyte film in the presence of $\mathrm{CaP}$ nanoclusters (Figure 17, curves $\alpha$-casein I., $\alpha$-casein II.). After a washing period, an attempt was made to adsorb $\alpha$-casein again, with no result (Figure 17, curve $\alpha$-casein III.). $\kappa$ casein, however, albeit in much lower amount than in the presence of $\mathrm{CaP}$, did adsorb onto the CaP-free $\alpha$-casein surface (Figure 17, curve $\kappa$-casein). The shape of the Amide I' band of this adsorbed $\kappa$-casein was similar to that was recorded in the case of $\mathrm{CaP}$ incorporation (Figure 16), the frequency downshift can be seen as well in both cases.

In order to answer the above mentioned question - whether $\mathrm{k}$-casein can terminate the aggregation process in $\mathrm{CaP}$-free conditions - further $\alpha$-casein adsorption was tested. Only a minute amount of $\alpha$-casein could adsorb onto this к-casein layer (Figure 17, curve $\alpha$-casein $I V$.). Therefore one could conclude that $\mathrm{k}$-casein is able to terminate the build-up of the protein multilayer. 


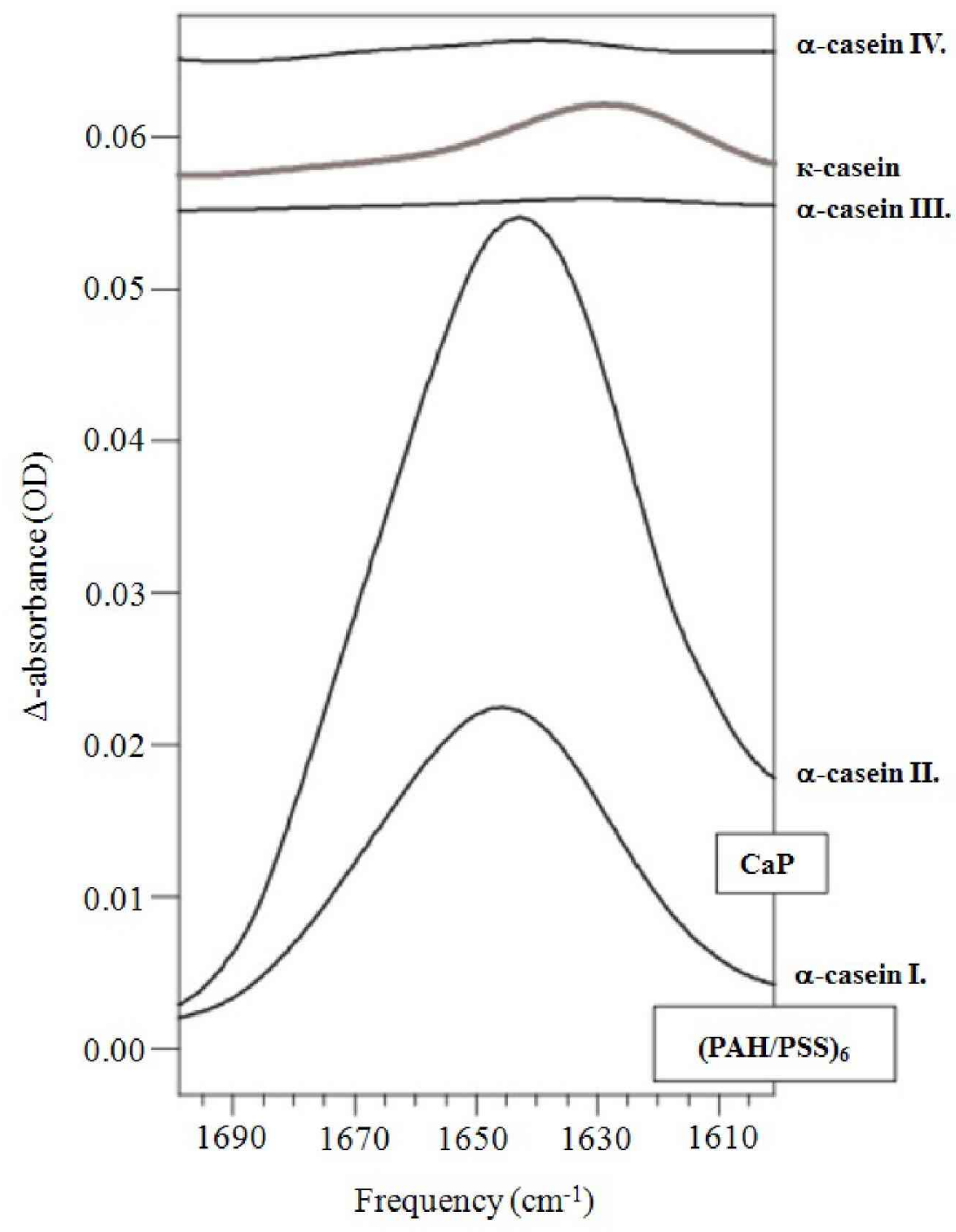

Figure 17. K-casein adsorption onto $\alpha$-casein in the absence of CaP nanoclusters: Amide I' regions of the incremental infrared spectra upon the construction of the protein multilayer. Steps of the architecture build-up are indicated along the right $\mathrm{y}$-axis.

To reveal whether $\kappa$-casein adsorption onto $\alpha$-casein surface alters the morphology and the elasticity of the aggregates, AFM measurements were carried out by recording height images on casein multilayers built up step-by-step. Every step was separated by a washing period (using $10 \mathrm{mM}$, pH 7 HEPES buffer), and all the measurements were done in tapping mode in HEPES buffer. Characteristic $1 \times 1 \mu \mathrm{m}^{2}$ height images recorded in one set of experiments can be seen in left column of Figure 18. 

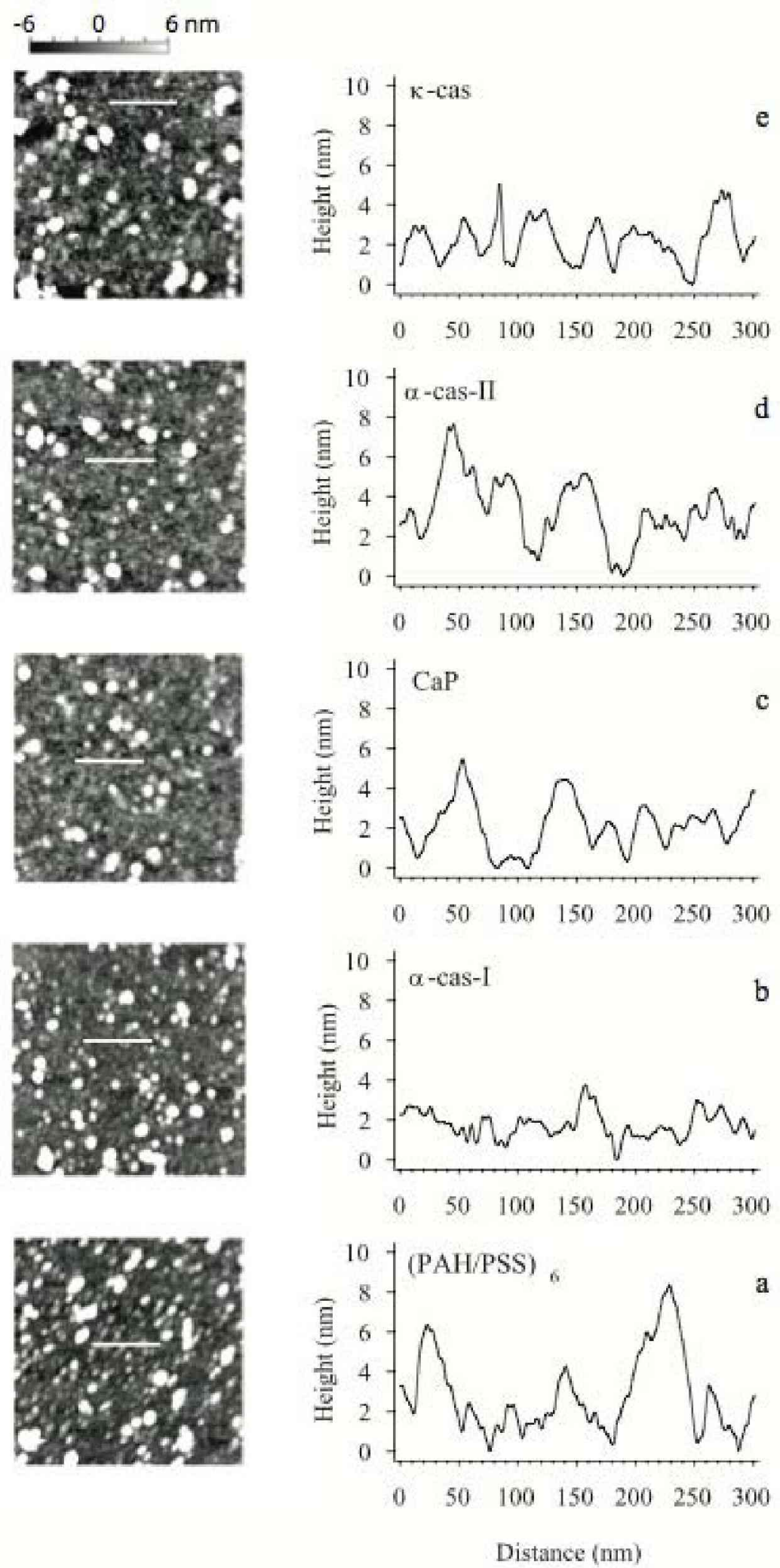

Figure 18. $1 \times 1 \mu \mathrm{m}^{2}$ height images and height profiles of a step-by-step built casein multilayer. White bars indicate the $300 \mathrm{~nm}$ traces where the corresponding height profiles were recorded. 
On the corresponding height profiles plotted in the right column of Figure 18, it can be seen that the first adsorbed $\alpha$-casein ( $\alpha$-cas-I) filled up the 'bumps' of the polyelectrolyte film surface. Formation of $\mathrm{CaP}$ on the $\alpha$-casein surface somewhat increased the surface roughness, which was not altered considerably upon the adsorption of the second $\alpha$-casein layer ( $\alpha$-casII). $\kappa$-casein - adsorbed in the absence of $\mathrm{CaP}$ - decreased somewhat the surface roughness of the underlying $\alpha$-cas-II layer. Looking at the images (Figure 18), no significant changes can be seen in the morphology of the multilayer surface. The topography of the protein surface in our model system shows similarity to surfaces of adsorbed native micelles, like in the study of Qi (Qi, 2007.).

The results of measuring the force accompanying the indentation of the cantilever are coherent with the information got from the height images and profiles. Figure 19 shows the force-indentation curves taken at every step of the architecture depicted in Figures 17 and 18.

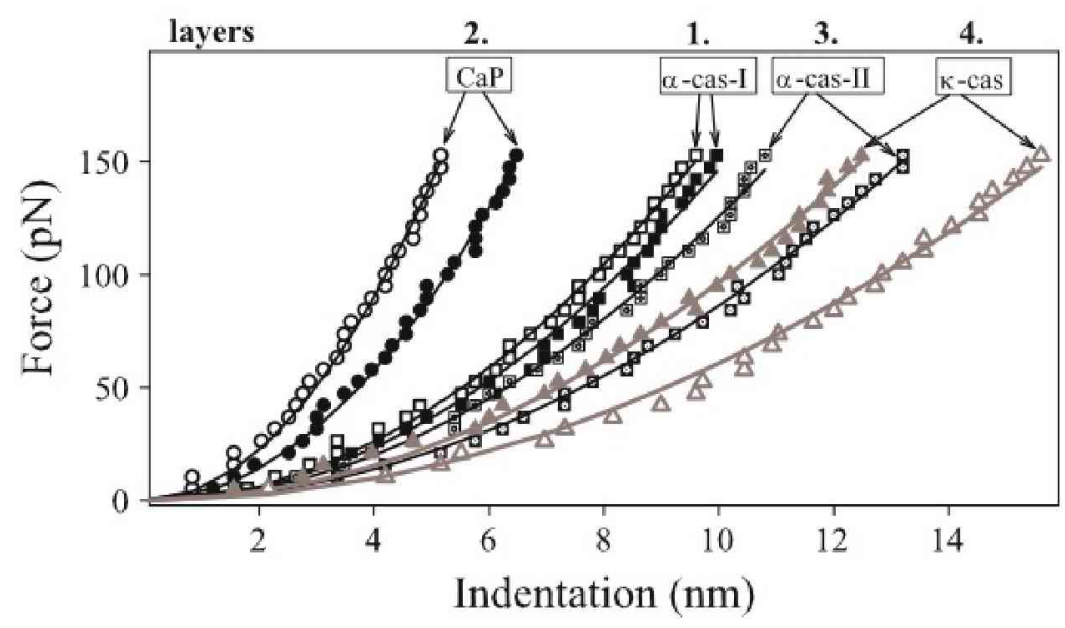

Figure 19. Force curves recorded upon the indentation of the cantilever of the AFM on different casein layers adsorbed onto (PAH/PSS) ${ }_{6}$ film. On the top of the figure, the numbers indicate the order of the adsorbed casein layer. For checking layer homogeneity, at each layer two data sets are shown at different places; each data point is the average of five force measurements.

Upon creating $\mathrm{CaP}$ nanoclusters on the first $\alpha$-casein layer the protein film becomes more rigid (Figure 19, CaP curves) and it softens back upon the second $\alpha$-casein adsorption (Figure 19, $\alpha$-cas-II curves). Upon adsorbing $\kappa$-casein onto the second $\alpha$-casein layer without forming $\mathrm{CaP}$ nanoclusters in between - some further softening appears. This softening could be ascribed simply to the presence of the larger amount of protein on the surface. The larger thickness upon the $\mathrm{k}$-casein adsorption onto the $\alpha$-casein results in a larger 
indentation of the AFM cantilever. The softening upon $\kappa$-casein adsorption is similar to that seen from one $\alpha$-casein layer to another; i.e. the general physical parameters of the $\kappa$ - and the $\alpha$-casein layers should be also similar.

\subsubsection{Summing the observations about the casein multilayers}

To understand the Ca-phosphate carrying capacity of the casein micelles, the structure and the construction principle of these micelles have to be understood. Our approach, utilizing casein monolayers fixed on a charged surface, made possible to study individual steps of casein aggregation.

Our experiments are unique in the sense that very low casein concentration $(0.1 \mathrm{mg} / \mathrm{ml})$ was used in contrast to the $60-100 \mathrm{mg} / \mathrm{ml}$ values of all other experiments. Thus, one may assume that casein molecules were adsorbed onto the polyelectrolyte surface in their "most natural' forms, 'one by one'. Therefore, it is remarkable that the surface roughness we observed came mostly from the presence of spherical features of about $20 \mathrm{~nm}$ in diameter. Such spheres were observed in earlier AFM measurements by Müller-Buschbaum et al. and were referred as mini micelles (Müller-Buschbaum et al., 2007). Small features of similar sizes were also observed in many earlier experiments, and lead to the sub-micelle conception of casein micelles.

Casein, when adsorbed on a positive surface (PAH ending polyeletrolyte film) could not bind any $\mathrm{CaP}$. On a positively charged surface, the negatively charged phosphoseryl residues (arranged in clusters) seem to be involved in the adsorption. This phenomenon supports that (i) the phosphorylated groups are on the surface of the casein, and (ii) they are, indeed, necessary for the micelle formation.

Being capable of adsorbing onto a negatively charged surface indicates that casein possesses certain amount of positive surface charges as well. This arrangement makes sure that the negative phosphoseryl residues of the casein do not participate in the adsorption; they remain accessible for further interactions. Indeed, these caseins could interact with $\mathrm{CaP}$ nanoclusters and $\mathrm{Ca}^{2+}$-ions. Once the $\mathrm{CaP}$ was incorporated into the casein, it opened the way for further casein adsorption and the build-up of a casein multilayer could be achieved (Figure 13). 
The most remarkable finding of this study is that only $\kappa$-casein has the capacity to get adsorbed onto $\alpha$-casein without $\mathrm{CaP}$. In opposite order, $\alpha$-casein was not adsorbed either on $\alpha$ or $\kappa$-casein surface (Figure 17). Without the presence of $\mathrm{CaP}$ nanoclusters, $\kappa$-casein adsorption is always accompanied with the emergence of considerable amount of $\beta$-structures, while the structure of $\alpha$-casein remains roughly the same (Figure 16.). It is not clear however, whether $\kappa$-casein suffers this structural change due to interaction with the $\mathrm{CaP}$ nanoclusters or with other proteins. The character of the changes appearing in the presence and in the absence of $\mathrm{CaP}$ formation was very similar. Even in the absence of $\mathrm{CaP}$ nanoclusters on the last $\alpha-$ casein layer, some $\mathrm{CaP}$, due to the non-complete covering of the last $\alpha$-casein layer could remain accessible for the more flexible $\kappa$-casein molecules.

These results suggest that similar thing might happen in vivo; $\kappa$-caseins adsorbing onto $\alpha$-casein may provide such a casein micelle surface, which cannot bind any more casein, thus the growth of the casein micelle terminates. In addition, a surface being made from $\kappa$-casein could provide the hairy structure needed for the solubility and the stability of the casein micelles in vivo.

This part of the work was published in the Journal of Biological Chemistry and the European Biophysics Journal (see Publication List No. II. and III.) 


\section{Conclusions}

The self-assembly of air-dried 18 mer oligonucleotides onto mica surface were studied by atomic force microscope imaging techniques. The structures formed by the oligonucleotides under different physical-chemical conditions were visualized at high resolution. We defined the optimal parameters (concentration and $\mathrm{pH}$ ) for the appearance of thread-like formations that are close to the morphology of the in vivo strands.

- Increasing the concentration of the ODN-solution, the evolving structures are getting more and more complex. At the beginning there are small spots, then strands and eventually complex networks could be observed on the muscovite mica surface. For the thread-like formations $20 \mathrm{nM}$ solution was the most suitable.

- As we expected, $\mathrm{pH}$ has an important role in the assembly of the appearing structures. The optimal $\mathrm{pH}$ for the in vivo-like strands fell in a very narrow, rather acidic range: $\mathrm{pH} 3.4-4.0$.

- We conclude that the surface must also play an important role in the selfassembly of the surface-dried molecules. This assembly seems to be conditioned by the presence of the localized positive charges on a smooth crystalline surface. These charges can interact with the strongly negativecharged ODNs to deposit in ordered structures.

The understanding of the self-assembly of the ODN could result in important contributions, both in basic research and technical applications. It is important to understand all the details of the self-assembly of nucleic acids, because these are the molecules which store all the information about living cells. By learning all the parameters governing the process, new applications of the molecules could be conceived.

The structure and the construction principle of casein micelles have been studied by letting $\alpha$-casein adsorb onto positively or negatively charged surfaces of polyelectrolyte films from low-concentration $(0.1 . \mathrm{mg} / \mathrm{ml})$ solutions. AFM and FTIR experiments have been carried out. 
- Casein could adsorb onto both positively and negatively charged surfaces, however only casein that adsorbed on negatively charged PSS-ending films was capable for to interact with $\mathrm{CaP}$. This observation suggests that phosphoseryl residues of caseins are involved in the micelle formation.

- From our experiments we can conclude that the protein first should interact with $\mathrm{Ca}^{2+}$-ions and only after that, it is capable to bind the phosphate-ions as well. Once the $\mathrm{CaP}$ was incorporated into the casein, it opens the way for further casein adsorption. We managed to build up casein multilayers from $\alpha$ and $\mathrm{k}$-caseins by using $\mathrm{CaP}$ treatment between each step.

- We have found that only $\kappa$-casein had the capacity to get adsorbed onto $\alpha$ casein without the presence of $\mathrm{CaP}$ nanoclusters. The adsorption of к-casein happens always together with the appearance of $\beta$-structures.

- These results suggest that similar thing might happen in vivo; $\kappa$-caseins adsorbing onto $\alpha$-casein may provide such a casein micelle surface, which cannot bind any more casein, thus the growth of the micelle terminates.

- Studying the topography of the planar protein layers, spherical features of about few tens of $\mathrm{nm}$ in diameter could be observed. Concerning our experimental conditions, one may assume that these roughly $20 \mathrm{~nm}$-sized spheres represent an inherent aggregating property of the casein molecules.

- Elasticity measurements have also been carried out, and they are in excellent agreement with the conclusions taken from the FTIR experiments. The most relevant observation was the extreme hardening effect of $\mathrm{CaP}$ treatment on caseins.

Summarizing the above conclusions, we propose that casein micelles are built up from about $20 \mathrm{~nm}$-sized casein aggregates, which are kept together by hydrophobic interaction, and have both positive and negative charges at their protein-water interface. The negative charges are the phosphoseryl residues, to which the Ca-phosphate nanoclusters can bind. In the next step of micelle build up, again $20 \mathrm{~nm}$-sized casein aggregates bind to the Ca-phosphate nanoclusters, but with their positive charges, then again $\mathrm{Ca}$-phosphate binding happens, and so on. $\kappa$-casein molecules can bind to the $20 \mathrm{~nm}$-sized $\alpha$-casein aggregates even in the absence 
of Ca-phosphate. By its 'soft' secondary structure, via producing $\beta$-sheets, $\kappa$-casein can cover the $\mathrm{Ca}$-phosphate binding sites of the $\alpha$-casein aggregates and terminate the casein micelle build-up. This model resolves the contradictions between the former models, and is in good agreement with the majority of the experimental data published so far. 


\section{Reference List}

Allemand, J.-F., Bensimon, D., Jullien, L., Bensimon, A. and Croquette, V. (1997): pHdependent specific binding and combining of DNA. Biophysical Journal, 73. 2064-2070.

Anselmetti, D., Fritz, J., Smith, B. and Fernandez-Busquets, X. (2000): Single molecule DNA biophysics with atomic force microscopy. Single Molecules, 1. 53-58.

Arrondo, J. L., Muga, A., Castresana, J. and Goni, F. M. (1993): Quantitative studies of the structure of proteins in solution by fourier-transform infrared spectroscopy. Progress in Biophysics and Molecular Biology, 59. 23-56.

Bálint, Z., Krizbai, I. A., Wilhelm, I., Farkas, A. E., Párducz, Á., Szegletes, Zs. and Váró, Gy. (2007): Changes induced by hyperosmotic mannitol in cerebral endothelial cells: an atomic force microscopic study. Eur. Biophys. J. 36. 113-120.

Bálint, Z., Nagy, K., Laczkó, I., Bottka, S., Végh, G. A., Szegletes, Zs., Váró Gy. (2007): Adsorption and Self-Assembly of Oligodeoxynucleotides onoto a Mica Surface, Journal of Physical Chemistry C, 111. 17032-17037.

Benkirane-Jessel, N., Schwinté, P., Falvey, P., Darcy, F., Haikel, Y., Schaaf, P., Voegel, J. C. and Ogier, J. (2004): Build-up of polypeptide multilayer coatings with anti-inflammatory properties based on the embedding of priroxicam-cyclodextrin complexes. Advanced Functional Materials, 14. 174-182.

Bennink, M. L., Nikova, D. N., van der Werf, K. O. and Greve, J. (2003): Dynamic imaging of single DNA-protein interactions using atomic force microscopy. Analytica Chimica Acta, 479. 3-15

Bernal, J. D. (1951): The physical basis of life. Routledge and Kegan Paul, London.

Berry, L. G., Mason, B., Dietrich, R. V. (1983): Mineralogy: concepts, descriptions, determinations, $2^{\text {nd }}$ ed., Freeman, W. H. and Co., New York.

Binnig G. and Rohrer, H. (1984): Scanning tunneling microscopy. Trends in Physics, 38-46. 
Binnig G., Quate C. F. and Gerber Ch. (1986): Atomic Force Microscope. Physical Review Letters, 56. 930-933.

Boudou, T., Crouzier, T., Ren, K., Blin, G. and Picart, C. (2009): Multiple functionalities of polyelectrolyte multilayer films: new biomedical applications. Advanced Materials, 21 1-27.

Braet, F., deZanger, R. and Wisse, E. (1997): Drying cells for SEM, AFM and TEM by hexamethyldisilazane: a study on hepatic endothelial cells. Journal Of Microscopy-Oxford, 186. 84-87.

Butt, H.-J., and Jaschke, M. (1995): Calculation of thermal noise in atomic force microscopy. Nanotechnology, 6 (1). 1-7.

Cattaruzza, F., Cricenti, A., Flamini, A., Girasole, M., Longo, G., Prosperi, T., Andreano, G., Cellai, L. and Chirivino, E. (2006): Controlled loading of oligodeoxyribonucleotide monolayers onto unoxidized crystalline silicon; fluorescence-based determination of surface coverage and of the hybridization efficiency; parallel imaging of the process by Atomic Force Microscopy. Nucleic Acids Research, 34. (4) e32.

Cheung, M. K. L., Trau, D., Yeung, K. L., Carles, M. and Sucher, N. J. (2003): 5 '-thiolated oligonucleotides on (3'-mercaptopropyl)trimethoxysilane-mica: surface topography and coverage. Langmuir, 19. 5846-5850.

Costa, L. T., Kerkmann, M., Hartmann, G., Endres, S., Bisch, P. M., Heckl, W. M. and Thalhammer, S. (2004): Structural studies of oligonucleotides containing G-quadruplex motifs using AFM. Biochemical and Biophysical Research Communications, 313. 1065-1072.

Decher, G. (1997): Fuzzy nanoassemblies: toward layered polymeric multicomposites. Science, 277. 1232-1237.

Eckle, M. and Decher, G. (2001): Tuning the performance of layer-by-layer assembled organic light emitting diodes by controlling the position of isolating clay barrier sheets. Nano Letters, 1. 45-49. 
Etiene, O., Gasnier, C., Taddei, C., Voegel, J. C., Aunis, D., Schaaf, P., Metz-Boutigue, M. H., Bolcato-Bellemin, A. L. and Egles, C. (2005): Antifungal coating by biofunctionalized polyelectrolyte multilayered films. Biomaterials, 26. 6704-6712.

Farrell, H. M. Jr., Malin, E. L., Brown, E. M. and Qi, P. X. (2006): Casein micelle structure: What can be learned from milk synthesis and structural biology? Current Opinion in Colloid and Interface Science, 11. 135-147.

Ferris, J. P. (2005): Mineral catalysis and prebiotic synthesis: montmorillonite-catalyzed formation of RNA. Elements, 1. 145-149.

Franchi, M., Ferris, J. P. and Gallori, E. (2003): Cations as mediators of the adsorption of nucleic acids on clay surfaces in prebiotic environments. Origin of Life and Evolution of the Biosphere, 33. 1-16.

Gebhardt, R., Doster, W., Friedrich, J. and Kulozik, U. (2006): Size distribution of pressuredecomposed casein micelles studied by dynamic light scattering and AFM. European Biophysics Journal with Biophysics Letters, 35. 503-509.

Gergely, Cs., Bahi, S., Szalontai, B., Flores, H., Schaaf, P., Voegel, J.-C. and Cuisinier, F. J. G. (2004): Human serum albumin self-assembly on weak polyelectrolyte multilayer films structurally modified by $\mathrm{pH}$ changes. Langmuir, 20. 5575-5582.

Goksu, E. I., Vanegas, J. M., Blanchette, C. D., Lin, W. C. and Longo, M. L. (2009): AFM for structure and dynamics of biomembranes. Biochimica et Biophysica Acta, 1788. 254-256.

Gong, H., Garcia-Turiel, J., Vasilev, K. and Vinogradova, O. I. (2005): Interaction and adhesion properties of polyelecrolyte multilayers. Langmuir, 21. 7545-7550.

Hansma, H. G., Revenko, I., Kim, K. and Laney, D. E. (1996): Atomic force microscopy of long and short double-stranded, single-stranded and triple-stranded nucleic acids. Nucleic Acids Research, 24. 713-720.

Hansma, H. G., Kim, K., Laney, D. E., Garcia, R. A., Argaman, M., Allen, M. J. and Parsons, S. M. (1997): Properties of biomolecules measured from atomic force microscope images: A review. Journal of structural biology, 119. 99-108. 
Hertz, M. G. (1881): Uber die Beruhrung Fester Elastischer Korper. J. Reine Angew. Math., 92. 156-171.

Holt, C., De Kruif, C. G., Tuinier, R., and Timmins, P. A. (2003): substructure of bovine casein micelles by small angle X-ray and neutron scattering. Colloids and Surfaces A, 203. 275-284.

Horne, D. S. (2002): Casein structure, self-assembly and gelation. Current Opinion in Colloid and Interface Science, 7. 456-461.

Hutter, J. L. and Bechhoefer, J. (1993): Calibration of atomic-force microscope tips. Review of Scientific Instrument, 64 (7). 1868-1873.

Karsai, Á., Grama, L., Murvai, Ü., Soós, K., Penke, B. and Kellermayer, M. S. Z. (2007): Potassium-dependent oriented growth of amyloid $\beta 25-35$ fibrils on mica. Nanotechnology, 18. 345102 .

Karsai Á., Murvai, Ü., Soós, K., Penkte, B., Kellermayer, M. S. Z. (2008): Oriented epitaxial growth of amyloid fibrils of the N27C mutant $325-35$ peptide. Europian Biophysics Journal, 37. 1133-1137.

Kellermayer, M. S. Z., Bustammante, C. and Granzier, H. L. (2003): Mechanics and structure of titin oligomers explored with atomic force microscopy. Biochimica et Biophysica ActaBioenergetics, 1604. 105-114.

Kirat, K. E., Morandat, S. and Dufrene, Y. F. (2010): Nanoscale analysis of supported lipid bilayers usong atomic force microscopy. Biochimica et Biophysica Acta, 1798. 750-765.

Laczkó, I., Váró, Gy., Bottka, S., Bálint, Z., Illyés, E., Vass, E., Bertrand, J.-R., Malvy, C. and Hollósi, M. (2006): N-terminal acylation of the SV40 nuclear localization signal peptide enhances its oligonucleotide binding and membrane transclocation efficiencies. Archives of Biochemistry and Biophysics, 454. 146-154.

Ladam, G., Schaaf, P., Decher, G., Voegel, J.-C. and Cuisinier, F. J. G. (2002): Protein adsorption onto auto-assembled polyelectrolyte films. Biomolecular Engineering, 19. 273280 . 
Lavalle, Ph., Gergely, Cs., Cuisinier, F. J. G., Decher, G., Schaaf, P., Voegel, J. C. and Picart, C. (2002): Comparison of the structure of polyelectrolyte multilayer films exhibiting a linear and an exponential growth regime: an in situ atomic force microscopy study.Macromolecules, 35. 4458-4465.

Martin, A. H., Goff, H. D., Smith, A., Dalgleish, D. G. (2006): Immobilization of casein micelles for probing their structure and interactions with polysaccharides using scanning electron microscopy (SEM). Food Hydrocolloids, 20. 817-824.

Mathur, A. B., Collinsworth, A. M., Reichert, W. M., Kraus, W. E. and Truskey, G. A. (2001): Endothelial, cardiac muscle and skeletal muscle exhibit different viscous and elastic properties as determined by atomic force microscopy. Journal of Biomechanics, 34. 15451553.

Menchaca, J.-L., Jachimska, B., Cuisinier, F. and Pérez, E. (2003): In situ surface structure study of polyelectrolyte multilayers by liquid-cell AFM. Colloids and Surfaces A: Physicochemical and Engineering Aspects, 222. 185-194.

Mermut, O., Lefebvre, J., Gray, D. G. and Barrett, C. J. (2003): Structural and mechanical properties of polyelectrolyte multilayer films studied by AFM. Marcomolecules, 36. 88198824.

Morandat, S. and Kirat, K. E. (2011): Cytochrome c provokes the weakening of zwitterionic membranes as measured by force spectroscopy. Colloids and Surfaces B: Biointerfaces, 82 . 111-117.

Mourougou-Candoni, N., Naud, C. and Thibaudau, F. (2003): Adsorption of thiolated oligonucleotides on gold surfaces: an atomic force microscopy study. Langmuir, 19. 682-686.

Müller-Buschbaum, P., Gebhardt, R., Roth, S. V., Metwalli, E. and Doster, W. (2007): Effect of calcium concentration on the structure of casein micelles in thin films. Biophysical Journal, 93. $960-968$.

Muller, D. J., Schabert, F. A., Buldt, G. and Engel, H. A. (1995): Imaging purple membrane in aqueous-solutions at subnanometer resolution by atomic force microscopy. Biophysical Journal, 68. 1681-1686. 
Muller, D. J., Schoenenberger, C. A., Schabert, F. A. and Engel, H. A. (1997): Structural changes in native membrane proteins monitored at subnanometer resolution with the atomic force microscope: A review. Journal of Structural Biology, 119. 149-157.

Munoz-Serrano, L., Guadalupe, A. R. and Vega-Bermudez, E. (2005): Morphological studies of oligodeoxyribonucleotides probes covalently immobilized at polystyrene modified surfaces. Journal of Biotechnology, 118. 233-245.

Nagy, K., Pilbat, A., Groma, G., Szalontai, B., Cuisinier, F. J. G. (2010): Casein Aggregates Built Step-by-step on Charged Polyelectrolyte Film Surfaces are Calcium Phosphatecemented, Journal of Biological Chemistry, 285. 38811-38817.

Nagy, K., Váró, Gy., Szalontai, B. (2012): K-casein terminates casein micelle build-up by its 'soft' secondary structure, European Biophysics Journal, submitted

Nakao, H., Hayashi, H., Iwata, F., Karasawa, H., Hirano, K., Sugiyama, S. and Ohtani, T. (2005): Fabricating and Aligning $\pi$-Conjugated Polymer-Functionalized DNA Nanowires: Atomic Force Microscopic and Scanning Near-Field Optical Microscopic Studies. Langmuir, 21. 7945-7950.

Oberleithner, H., Schneider, S. W., Albermann, L., Hillebrand, U., Ludwig, T., Riethmuller, C., Shahin, V., Schafer, C. and Schillers, H. (2003): Endothelial cell swelling by aldosterone. Journal of Membrane Biology, 196. 163-172.

Pan, X., Shaoyong, Y., Yao, P. and Shao, Z. (2007): Self assembly of $\beta$-casein and lysozyme. Journal of Colloid and Interface Science, 316. 405-4012.

Paquim, A. C., Oretskaya, T. S., Brett, A. O. (2006): Adsorption of synthetic homo-and hetero-oligodeoxynucleotides onto highly oriented pyrolytic graphite: Atomic force microscopy characterization. Biophysical Chemistry, 121. 131-141.

Picart, C. (2008): Polyelectrolyte multilayer films: from physic-chemical properties to the control of cellular processes. Current Medicinal Chemistry, 15. 658-697. 
Pilbat, A.-M., Ball, V., Schaaf, P., Voegel, J.-C. and Szalontai, B. (2006): Partial poly(glutamic acid)↔ poly(aspartic acid) exchange in layer -by-layer polyelecrolic films. Structural alterations in the three-component architectures. Langmuir, 22. 5753-5759.

Pilbat, A.-M., Szegletes, Zs., Kóta, Z., Ball, V., Schaaf, P., Voegel, J.-C. and Szalontai, B. (2007): Phospholipid bilayers as biomemrane-like barriers in layer-by-layer polyelectrolyte films. Langmuir, 23. 8236-8242.

Pontes-Buarque, M., Tessis, A. C., Bonapace, J. A. P., Monte, M. B. M., Souza-Barros, F. and Vieyra, A. (2000): Surface charges and interfaces: Implications for mineral roles in prebiotic chemistry. Anais da Academia Brasileira de Ciencias, 72. 317-322.

Qi, P. X. (2007): Studies of casein micelle structure: the past and the present. Le Lait, 87. 363383.

Richert, L., Lavalle, P., Vautier, D., Senger, B., Stoltz, J. F., Schaaf, P., Voegel, J. C. and Picart, C. (2002): Cell interactions with polyelectrolyte multilayer films. Biomacromolecules, 3. 1170-1178.

Schwinté, P., Ball, V., Szalontai, B., Haikel, Y., Voegel, J. C. and Schaaf, P. (2002): Secondary structure of proteins adsorbed onto or embedded in polyelectrolyte multilayers. Biomacromolecules, 3. 1135-1143.

Schwinté, P., Voegel, J. C., Picart, C., Haikel, Y., Schaaf, P. and Szalontai, B. (2001): Stabilizing effects of various polyelectrolyte multilayer films on the structure of adsorbed/embedded fibrinogen molecules: an ATR-FTIR study. Journal of Physical Chemistry B, 105. 11906-11916.

Sha, F., Mu, R., Henderson, D., Chen, F. (1999): Self-aggregation of DNA oligomers with XGG trinucleotide repeats: Kinetic and atimc force microscopy measurements. Biophysical Journal, 77. 410-423.

Shiratori, S. S. and Rubner, M. F. (2000): pH-Dependent Thickness Behavior of Sequentially Adsorbed layers of Weak Polyelectrolytes. Macromolecules, 33. 4203-4219. 
Sitko, J. C., Mateescu, E. M. and Hansma, H. G. (2003): Sequence-dependent DNA condensation and the electrostatic zipper. Biophysical Journal, 84. 419-431.

Sneddon, I. N. (1965): The relation between load and penetration in the axisymmetric Boussinesq problem for punch of arbitrary profile. Int. J. Engr. Sci., 3. 47-57.

Sowerby, S. J., Cohn, C. A., Heckl, W. M. and Holm N. G. (2001): Differential adsorption of nucleic acid bases: Relevance to the origin of life. Proceedings of the National Academy of Sciences USA, 98. 820-822.

Sowerby, S. J., Holm, N. G. and Petersen, G. B. (2001): Origin of life: a route to nanotechnology. BioSystems, 61. 69-78.

Szyk-Warszynska, L., Gergely, Cs., Jarek, E., Cuisinier, F., Socha, R. P. and Warszynski, P. (2009): Calcium uptake by casein embedded in polyelectrolyte multilayer. Colloids and Surfaces A: Physicochemical and Engineering Aspects, 343. 118-126.

Szyk, L., Schwinté, P., Voegel, J. C., Schaaf, P. and Tinland, B. (2002): Dynamical behavior of human serum albumin adsorbed on or embedded in polyelectrolyte multilayers. Journal of Physical Chemistry B, 106. 6049-6055.

Swaisgood, H. E. (1992): Chemistry of the caseins. Advanced Dairy Chemistry 1. Proteins. Elsevier, New York, 63-110.

Tompa, P. (2005): The interplay between structure and function in intrinsically unstructured proteins. FEBS Letters, 579. 3346-3354.

Uricanu, V. I., Duits, M. H., G., Mellema, J. (2004): Hierarchical networks of casein proteins: an elasticity study based on atomic force microscopy, Langmuir, 20. 5079-5090.

Végh, A. G., Fazakas, C., Nagy, K., Wilhelm, I., Krizbai, I. A., Nagyőszi, P., Szegletes, Z., Váró, G. (2011): Spatial and Temporal Dependence of the Cerebral Endothelial Cells Elasticity, Journal of Molecular Recognition, 24. 3. 422-428.

Vegh, A. G., Fazakas, C., Nagy, K., Wilhelm, I., Molnar, J., Krizbai, I., A., Szegletes, Z., Varo, G. (2012): Adhesion and stress relaxation forces between melanoma and cerebral endothelial cells, European Biophysics Journal with Biophysics Letters, 41. 139-145. 
Végh, A. G., Nagy, K., Bálint, Z., Kerényi, Á., Rákhely, G., Váró, G., Szegletes, Z. (2011): Effect of antimicrobial peptide-amide, indolicidin on biological membranes, Journal of Biomedicine and Biotechnology, 2011. 1-6.

Vessely, C. R., Carpenter, J. F. and Schwartz, D. K. (2005): Calcium-induced changes to the molecular conformation and aggregate structure of $\beta$-casein at the air-water interface. Biomacromolecules, 6. 3334-3344.

Vinckier, A. and Semenza, G. (1998): Measuring elasticity of biological materials by atomic force microscopy. Febs Letters, 430. 12-16.

Walstra, P. (1999): Casein sub-micelles. do they exists?. International Dairy Journal, 9. 189192.

Whitesides, G. M. and Grzybowski B. (2002): Self-assembly at all scales. Science, 295. 24182421.

Winfree, E., Liu, F., Wenzler, L. A. and Seeman, N. C. (1998): Design and self-assembly of two-dimensional DNA crystals. Nature, 394. 539-544.

Woodward, J. T. and Meuse, C. W. (2009): Mechanism of formation of vesicle fused phospholipid monolayers on alkanethiol self-assembled monolayer supports. Journal of Colloid and Interface Science, 334. 139-145.

Xiao, Z., Xy, M., Sagisaka, K. and Fujita, D. (2003): AFM observations of self-assembled lambda DNA network on silanized mica. Thin Solid Films, 438. 114-117.

Yan, H., Park, S. H., Finkelstein, G., Reif, J. H. and LaBean, T. H. (2003): DNA-templated self-assembly of protein arrays and highly conductive nanowires. Science, 301. 1882-1884. 
Annex 